\title{
Impaired cellular bioenergetics caused by GBA1 depletion sensitizes neurons to calcium overload
}

\author{
Nicoletta Plotegher ${ }^{1,8} \cdot$ Dany Perocheau ${ }^{2} \cdot$ Ruggero Ferrazza $^{3} \cdot$ Giulia Massaro $^{4} \cdot \mathbb{C}^{4}$ Gauri Bhosale ${ }^{1}$ • \\ Federico Zambon ${ }^{1}$ - Ahad A. Rahim ${ }^{4}$ - Graziano Guella ${ }^{3}$ Simon N. Waddington $\mathbb{C}^{2,5}$ • Gyorgy Szabadkai $\mathbb{D}^{1,6,7}$. \\ Michael R. Duchen (i) ${ }^{1}$
}

Received: 5 February 2019 / Revised: 9 October 2019 / Accepted: 10 October 2019 / Published online: 4 November 2019

(c) The Author(s) 2019. This article is published with open access

\begin{abstract}
Heterozygous mutations of the lysosomal enzyme glucocerebrosidase (GBAl) represent the major genetic risk for Parkinson's disease (PD), while homozygous GBAl mutations cause Gaucher disease, a lysosomal storage disorder, which may involve severe neurodegeneration. We have previously demonstrated impaired autophagy and proteasomal degradation pathways and mitochondrial dysfunction in neurons from GBAl knockout $\left(\mathrm{gbal}^{-/-}\right)$mice. We now show that stimulation with physiological glutamate concentrations causes pathological $\left[\mathrm{Ca}^{2+}\right]_{\mathrm{c}}$ responses and delayed calcium deregulation, collapse of mitochondrial membrane potential and an irreversible fall in the ATP/ADP ratio. Mitochondrial $\mathrm{Ca}^{2+}$ uptake was reduced in $\mathrm{gbal}^{-1-}$ cells as was expression of the mitochondrial calcium uniporter. The rate of free radical generation was increased in $\mathrm{gbal}^{-/-}$neurons. Behavior of $\mathrm{gbal}^{+/-}$neurons was similar to $\mathrm{gbal}^{-/-}$in terms of all variables, consistent with a contribution of these mechanisms to the pathogenesis of PD. These data signpost reduced bioenergetic capacity and $\left[\mathrm{Ca}^{2+}\right]_{\mathrm{c}}$ dysregulation as mechanisms driving neurodegeneration.
\end{abstract}

Edited by N. Bazan

Supplementary information The online version of this article (https:// doi.org/10.1038/s41418-019-0442-2) contains supplementary material, which is available to authorized users.

Michael R. Duchen

m.duchen@ucl.ac.uk

1 Cell and Developmental Biology Department, University College London, London WC1E6XA, UK

2 Institute for Women's Health, University College London, London WC1E6HU, UK

3 Department of Physics, University of Trento, 38123 Povo (TN), Italy

4 School of Pharmacy, University College London, London WC1N1AX, UK

5 MRC Antiviral Gene Therapy Research Unit, Faculty of Health Sciences, University of the Witwatersrand, Johannesburg, South Africa

6 Department of Biomedical Sciences, University of Padua, 35131 Padua, Italy

7 The Francis Crick Institute, London NW1 1AT, UK

8 Present address: Department of Biology, University of Padua, 35131 Padua, Italy

\section{Introduction}

The GBAl gene encodes for the lysosomal enzyme glucocerebrosidase (GBA1), which hydrolyzes the lipid glucosylceramide [1]. Homozygous mutations in GBAl cause an inherited lysosomal storage disease known as Gaucher disease (GD) [2], while heterozygous mutations in GBAl are the major known genetic risk factor for Parkinson's disease (PD) [3-5]. GD presents with a spectrum of symptoms and is classified into three 'types': [6] while type I shows limited or late CNS involvement, type II presents with a severe and progressive neurodegeneration, and type III with less severe, chronic neurological symptoms. PD signs and symptoms include resting tremors, bradykinesia, and rigidity; anosmia, depression, and anxiety, and at later stages, dementia. The links between specific GBA1 mutations and phenotype remain unclear [6, 7].

Both PD and lysosomal storage diseases such as GD are characterized by dysfunction of the autophagy/lysosomal pathway and impaired mitochondrial function [8, 9], suggesting that deficiencies in each of these pathways can affect the other [10]. We have previously shown that, in neurons from $\mathrm{gbal}^{-/-}$mice, autophagy is impaired upstream of the lysosome, associated with profoundly impaired mitochondrial 
function, decreased mitochondrial membrane potential $\left(\Delta \psi_{\mathrm{m}}\right)$, reduced mitochondrial respiration, and especially a dramatic decrease in uncoupled maximal respiratory capacity [11]. Interestingly, $g b a I^{+/-}$neurons showed a modest reduction in $\Delta \psi_{\mathrm{m}}$, reflecting the absence of symptoms in the $\mathrm{gbal}^{+/-}$mice compared with $\mathrm{gbal}^{-/-}$[12].

The mechanism linking mitochondrial dysfunction to the underlying primary defect in lysosomal biology remains unresolved but may be attributable to the accumulation of dysfunctional mitochondria due to impaired mitochondrial quality control pathways. This has also been described in other lysosomal storage diseases (reviewed in [8]).

Mitochondria show an intimate and complex relationship with calcium signaling, representing a major intersection between cellular bioenergetics and cell signaling pathways [13-15]. Mitochondria take up $\mathrm{Ca}^{2+}$ from the cytosol, in a process mediated by the mitochondrial $\mathrm{Ca}^{2+}$ uniporter (MCU) complex [16], its regulatory proteins [17-19], and balanced by the mitochondrial $\mathrm{Ca}^{2+}$ efflux pathway [20].

Dysregulation of $\left[\mathrm{Ca}^{2+}\right]_{\mathrm{c}}$ signaling has been implicated widely in neurodegeneration and has been identified as a key pathway in the selective degeneration of dopaminergic neurons in PD [21, 22]. We therefore explored the interplay between $\left[\mathrm{Ca}^{2+}\right]_{\mathrm{c}}$ homeostasis and mitochondrial bioenergetic capacity as potential contributors the neurodegeneration associated with $G B A 1$ depletion, studying $\left[\mathrm{Ca}^{2+}\right]_{\mathrm{c}}$ signaling in primary neuronal cultures from $\mathrm{gbal}^{-/-}, \mathrm{gbal}^{+-}$, and $\mathrm{gbal}^{+/+}$mice, stimulated with glutamate at physiological concentrations that are innocuous to control neurons $(10 \mu \mathrm{M}$ or below). $\mathrm{As} \mathrm{Ca}^{2+}$-dependent mitochondrial dysfunction is exacerbated by oxidative stress $[15,23]$, we also explored changes in free radical production associated with $G B A I$ depletion.

We found that in both $\mathrm{gbal}^{-/-}$and $\mathrm{gbal}^{+/-}$neurons, exposure to physiological glutamate concentrations caused delayed calcium deregulation (DCD), loss of $\Delta \psi_{\mathrm{m}}$ and bioenergetic failure. Intriguingly, MCU protein expression was downregulated in $\mathrm{gbal}^{-1-}$, associated with a reduced mitochondrial $\mathrm{Ca}^{2+}$ buffering capacity.

Very importantly, $\mathrm{gbal}^{+/}$neurons, which model to a certain extent the heterozygous GBAl mutations found in PD patients, behaved similarly to $\mathrm{gbal}^{-/-}$.

These findings emphasize the fundamental importance of mitochondrial bioenergetic capacity in maintaining neuronal energy homeostasis in the face of increased energetic demand associated with activity. Our data demonstrate the vulnerability of neurons in which mitochondrial function is perturbed to cellular $\left[\mathrm{Ca}^{2+}\right]_{\mathrm{c}}$ overload, suggesting that increased sensitivity to physiological glutamate concentrations may play an important role in neurodegeneration in GD and possibly also in GBA1-related PD.

\section{Methods and materials}

\section{Mouse model and animal welfare}

Mice used for this work were described in Enquist et al. [12]. As K14-wt, K14-lnl/wt (lox/neomycin/lox), and $\mathrm{K} 14-\operatorname{lnl} / \mathrm{lnl}$ and are herein referred as $\mathrm{gbal}^{+/+}, \mathrm{gbal}^{+/-}$, and $\mathrm{gbal}^{-/-}$.

Mouse welfare was approved by the University College London Animal Welfare and Ethical Review Board (AWERB) and in accordance with personal licenses granted by the UK Home Office and the Animal (Scientific Procedures) Act of 1986. The colony was maintained using breeding pairs heterozygous for GBA1 and pups were euthanized at $\mathrm{P} 0$ using cervical dislocation followed by decapitation for primary neuronal cultures preparation and liver extraction for genotyping.

\section{Mouse genotyping}

Genomic DNA was extracted from liver for each pup (P0) using DNeasy Blood \& Tissue Kit (Qiagen), genotyped by PCR using Q5 High Fidelity DNA Polymerase (NEB) and the following primers:

\section{GCex8-2 GTACGTTCATGGCATTGCTGTTCACT (Sigma, USA) \\ METex8-2 ATTCCAGCTGTCCCTCGTCTCC \\ (Sigma, USA) \\ NEO-AO2 AAGACAGAATAAAACGCACGGGTG (Sigma, USA) TTGG}

PCR was performed on T100 Thermal cycler (Biorad) using the following PCR cycling conditions. Bands were visualized by gel electrophoresis.

\begin{tabular}{lll}
\hline $98{ }^{\circ} \mathrm{C}$ & $30 \mathrm{~s}$ & $\times 15$ \\
$98{ }^{\circ} \mathrm{C}$ & $10 \mathrm{~s}$ & \\
$63^{\circ} \mathrm{C}\left(0.5^{\circ} \mathrm{C}\right.$ touchdown $)$ & $30 \mathrm{~s}$ & \\
$72^{\circ} \mathrm{C}$ & $1.30 \mathrm{~min}$ & \\
$98^{\circ} \mathrm{C}$ & $10 \mathrm{~s}$ & $\times 25$ \\
$61^{\circ} \mathrm{C}$ & $30 \mathrm{~s}$ & \\
$72^{\circ} \mathrm{C}$ & $1.30 \mathrm{~min}$ & \\
$72{ }^{\circ} \mathrm{C}$ & $5 \mathrm{mins}$ & \\
$10^{\circ} \mathrm{C}$ & Hold & \\
\hline
\end{tabular}




\section{Neuronal and astrocyte primary culture}

Mixed cultures of cortical neurons and astrocytes were obtained by dissecting brains from P0-P1 mice. Cortices from each brain were isolated, kept in HBSS (H6648, Sigma) on ice separated from each other and genotyping was performed on liver extracted from each pup.

Brain tissue was incubated in EBSS (E2888, Sigma) and papain (LK003178, Worthington Biochemical Corp.) for $40 \mathrm{~min}$ at $37{ }^{\circ} \mathrm{C}$ and it was then dissociated by trituration in EBSS supplemented with DNAse (LK003172, Worthington Biochemical Corp.) and papain inhibitor (LK003182, Worthington Biochemical Corp.). After spinning, the cell pellet was resuspended in Neurobasal (21103-049, Life Technologies), supplemented with B27 (17504-044, Life Technologies), Glutamax (35050-038, Life Technologies), and $100 \mathrm{U} / \mathrm{ml}$ Penicillin-Streptomycin (1514-122, Life Technologies) counted and plated to appropriate densities on coverslips $\left(0.5 \cdot 10^{6}\right.$ cells $)$, 6-well plates $\left(10^{6}\right.$ cells $)$ or 96 well plates (30000 cells), coated with polylysine (P4707, Sigma). Half media changes were done every 4 or 7 days. Cultures were maintained at $37^{\circ} \mathrm{C}$ and $5 \% \mathrm{CO}_{2}$ in humidified atmosphere and used between 10 and 15 days in vitro unless stated differently.

\section{Cytosolic calcium imaging}

Primary neurons and astrocytes in mixed cultures were seeded onto 22-mm coverslips (or on $35 \mathrm{~mm}$ FluoroDishes $^{\mathrm{TM}}$ (Fisherscientific)) and stained with $5 \mu \mathrm{M}$ FuraFF or Fura2 (F14181 and F1221, Thermo Fisher Scientific) in recording buffer $(150 \mathrm{mM} \mathrm{NaCl}, 4.25 \mathrm{mM} \mathrm{KCl}, 4 \mathrm{mM}$ $\mathrm{NaHCO}_{3}, 1.25 \mathrm{mM} \mathrm{NaH}_{2} \mathrm{PO}_{4}, 1.2 \mathrm{mM} \mathrm{CaCl}, 10 \mathrm{mM}$ D-glucose, and $10 \mathrm{mM}$ HEPES at $\mathrm{pH}$ 7.4) with pluronic acid $0.02 \%$, at $37{ }^{\circ} \mathrm{C}$ and $5 \% \mathrm{CO}_{2}$ for $30 \mathrm{~min}$.

After washing, cells were imaged in recording buffer using a custom-made imaging widefield system built on an IX71 Olympus microscope equipped with a 20x water objective. A Xenon arc lamp with a monochromator was used for excitation, exciting FuraFF or Fura2 fluorescence alternately at $340 \mathrm{~nm} \pm 20 \mathrm{~nm}$ and $380 \mathrm{~nm} \pm 20 \mathrm{~nm}$ and collecting emitted light through a dichroic T510lpxru or a 79003-ET Fura2/TRITC (Chroma), and a band-pass filter $535 / 30 \mathrm{~nm}$. Images were acquired using a Zyla CMOS camera (Andor) every $2-4 \mathrm{~s}$ and neurons were stimulated using $10 \mu \mathrm{M}$ glutamate (G1626, Sigma). A total of $2 \mu \mathrm{M}$ ionomycin was added at the end of each time course as a positive control.

Electrical stimulation experiments were performed using a 'myopacer' (Ionoptix, Westwood USA) electrical stimulator and custom-made platinum electrodes (settings were: $40 \mathrm{~V}, 5 \mathrm{~Hz} 40 \mathrm{msec}$ pulses and each stimulation period lasted $10 \mathrm{~s})$.
Activation of metabotropic glutamate receptors was achieved by challenging neurons with $100 \mu \mathrm{M}$ quisqualate (Q2128, Sigma), while inhibiting NMDA and AMPA/kainate receptors using $10 \mu \mathrm{M}(2 \mathrm{R})$-amino-5-phosphonopentanoate (D-AP5) $(0106 / 100$, Bio Techne Ltd) and $20 \mu \mathrm{M}$ CNQX (HB0205, HelloBio), respectively.

Images were analyzed using ImageJ by selecting regions of interest (ROI) in each cell and measuring average fluorescence intensity in the ROIs for each channel. After background subtraction, ratios between the signal excited at $380 \mathrm{~nm}$ and at $340 \mathrm{~nm}$ were calculated at each time point and the resulting 340/380 ratioed traces representing cytosolic $\left[\mathrm{Ca}^{2+}\right]_{\mathrm{c}}$ levels upon stimulation were plotted. Peak amplitude values were calculated for each cell using Microsoft Excel and GraphPrism.

\section{Rhodamine123 imaging}

Mixed cultures of primary neurons and astrocytes seeded on 22-mm coverslips were labeled with $10 \mu \mathrm{g} / \mathrm{ml}$ Rhodamine123 (R8004, Sigma) in recording buffer, at $37^{\circ} \mathrm{C}$ and $5 \% \mathrm{CO}_{2}$ for $20 \mathrm{~min}$. After washing, cells were imaged in recording buffer using a Zeiss 880 confocal microscope equipped with a $40 \times$ oil objective, exciting neurons at $488 \mathrm{~nm}$ and collecting light longer than $505 \mathrm{~nm}$. Images were acquired every $20 \mathrm{~s}$ with low laser power to avoid lightinduced mitochondrial depolarization and photobleaching. Neurons were stimulated using $10 \mu \mathrm{M}$ glutamate (G1626, Sigma) and $1 \mu \mathrm{M}$ Carbonyl cyanide 4-(trifluoromethoxy) phenylhydrazone (FCCP) (C2920, Sigma) was added at the end of the time course to evaluate the Rhod123 fluorescence intensity corresponding to $100 \%$ depolarization. Images were analyzed using ImageJ by selecting ROI in each field and measuring average fluorescence intensity in the ROIs. For each trace, the signal was normalized between basal (the minimum value of intensity set to $0 \%$ ) while the fully depolarized signal was set as the intensity of the maximal data point, representing complete depolarization, at $100 \%$. Cumulative frequency distribution analysis was also performed as for the measurements of $\left[\mathrm{Ca}^{2+}\right]_{\mathrm{c}}$.

\section{Western blotting}

Brains tissue dissection was performed at $\mathrm{P} 0-\mathrm{P} 1$ and samples were snap frozen in liquid nitrogen and stored at $-80^{\circ} \mathrm{C}$. To extract soluble proteins, brain tissue was homogenized in RIPA buffer $(150 \mathrm{mM} \mathrm{NaCl}, 0.5 \%$ Sodium deoxycholic acid, $0.1 \%$ SDS, $1 \%$ Triton $\mathrm{X}-100,50 \mathrm{mM}$ Tris $\mathrm{pH} 8.0$, $1 \mathrm{mM}$ PMSF (93482, Sigma)) and incubated $30 \mathrm{~min}$ on ice. After incubation, lysates were centrifuged and the soluble fraction was collected to quantify protein concentration by Pierce BCA Protein Assay Kit (23225, Thermo Scientific). Sample buffer $4 \times$ with $2 \%$ beta-meracapto ethanol was 
added to 30-50 ug of total proteins, samples were boiled and loaded onto a Nu-Page gel (4-12\% or 12\%) (NP0335 and NP0341, Invitrogen) using MOPS or MEF buffer (NP001 or NP002, Invitrogen). Gels were transferred to $0.45 \mu \mathrm{m}$ PVDF membranes (IPVH00010, Millipore) in transfer buffer (NP0006, Invitrogen) with 20\% methanol using a semi-dry system (Invitrogen).

After blocking in 5\% milk T-TBS buffer $(20 \mathrm{mM}$ Tris,

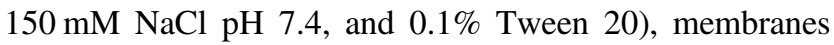
were probed with primary antibodies (MCU, HPA016480 Sigma; EMRE, sc-86337 Santa Cruz; SOD1, sc-8637 Santa Cruz; SOD2, sc-137254 Santa Cruz; grp75, sc-1058 Santa Cruz; $\beta$-actin, A2228 Sigma; MICU2, ab101465 Abcam; MCURI, ab86335, Abcam; GRIN2b, AGC-003 Alomone labs; GRIK2, AGC-009 Alomone labs; Phospho-p40phox (Thr154), \#4311 Cell Signaling Technology) overnight at $4{ }^{\circ} \mathrm{C}$, washed and probed with an appropriate HRPconjugated secondary antibody (anti-rabbit, 31463 Thermo Fisher Scientific; anti-mouse, 31457 Thermo Fisher Scientific; anti-goat, A5420 Sigma) for $1 \mathrm{~h}$ at room temperature. Visualization was performed using Luminata Forte Western HRP substrate (WBLUF0100, Millipore) and Chemidoc imaging system (Biorad).

\section{ATP:ADP measurements using PercevalHR and confocal imaging}

A total of 30,000-50,000 neurons were plated in 96-well plates with clear bottom and transfected with the ATP:ADP sensor PercevalHR [24] at DIV8 using Lipofectamine LTX (15338-030, Life Technologies) in Optimem (31985-047, Life Technologies) for $1 \mathrm{~h}$. Conditioned media were kept and used to replace Optimem after transfection. After 48-72 h, imaging of single neurons expressing PercevalHR was performed in recording buffer exciting PercevalHR at $405 \mathrm{~nm}$ and at $488 \mathrm{~nm}$ and collecting light at wavelengths longer than $510 \mathrm{~nm}$, using a Zeiss 880 confocal microscope. Images were acquired every $10 \mathrm{~s}$ and neurons were stimulated using $10 \mu \mathrm{M}$ glutamate (G1626, Sigma) at $200 \mathrm{~s}$. ATP: ADP ratios over time were obtained drawing ROIs in each neuron, measuring average fluorescence intensity in the ROIs for each channel in ImageJ and calculating the 488 $\mathrm{nm} / 405 \mathrm{~nm}$ ratio.

\section{Mitochondrial calcium measurement using mitochondrial-aequorin}

A total of 30,000-50,000 mixed neurons and astrocytes were plated and grown onto white 96-well plates, transduced with mtAequorin adenovirus [25] at DIV7-8 and incubated for $48-72 \mathrm{~h}$. Afterward, media was replaced with $5 \mu \mathrm{M}$ coelenterazine in Krebs Ringer Buffer $(125 \mathrm{mM} \mathrm{NaCl}$, $5.5 \mathrm{mM}$ D-Glucose, $5 \mathrm{mM} \mathrm{KCl}, 20 \mathrm{mM}$ HEPES, $1 \mathrm{mM}$
$\mathrm{Na}_{3} \mathrm{PO}_{4}, 1 \mathrm{mM}$ Glutamine, $100 \mathrm{mM}$ Pyruvate, and $1.2 \mathrm{mM}$ $\mathrm{CaCl}_{2}$ ). The plate was then incubated in the dark for $2 \mathrm{~h}$ at $37^{\circ} \mathrm{C}$. Luminescence measurements were obtained using a plate reader (FluoStar Optima, BMG Labtech) every $1 \mathrm{~s}$ after $10 \mu \mathrm{M}$ glutamate stimulation at $5 \mathrm{~s}$. A total of $100 \mu \mathrm{M}$ Digitonin was added at $25 \mathrm{~s}$. Mitochondrial $\mathrm{Ca}^{2+}$ concentrations were calculated as previously described [25].

\section{Measurement of rates of ROS generation}

Mixed neurons and astrocytes plated on coverslips were imaged in recording buffer using a Zeiss 510 confocal microscope, equipped with a UV laser (Coherent). $5 \mu \mathrm{M}$ dihydroethidium (DHE, D1168 Thermo Fisher Scientific) was added to recording buffer after starting the acquisition. Reduced DHE was excited at $351 \mathrm{~nm}$ and emitted light was recorded between 435 and $485 \mathrm{~nm}$; oxidized DHE was excited at $543 \mathrm{~nm}$ and emitted light was collected using a 560-nm long-pass filter. Images were acquired over time every $8.93 \mathrm{~s}$ and $10 \mu \mathrm{M}$ glutamate was added at $600 \mathrm{~s}$ to measure changes induced by glutamate stimulation in oxidation rates. Oxidation rate curves were obtained calculating the ratio between reduced and oxidized DHE. Basal oxidation levels (basal slopes) were calculated considering the difference between ratio at $500 \mathrm{~s}$ and the ratio at the beginning of the time course and dividing it by the time duration. Glutamate-induced oxidation rates were calculated as the difference between ratios at $1000 \mathrm{~s}$ and at $500 \mathrm{~s}$ and dividing it by the time duration (glutamate slopes).

\section{Measurement of glutathione levels using monochlorobimane (MBC)}

Monocholorobimane (M1381MP, Invitrogen) imaging experiments were performed further adapting a protocol set for neurons [26]. Briefly, neurons plated on coverslips as previously described and were incubated with $100 \mu \mathrm{M}$ MCB in recording buffer until a steady state was achieved. Images were acquired using a custom-made widefield imaging system built on an IX71 Olympus microscope equipped with a $20 \times$ water objective. A Xenon arc lamp with a monochromator was used for excitation set at $380 \mathrm{~nm}$ and collecting emitted light through a dichroic mirror 79001-ET Fura2 (Chroma) and a band-pass emission filter at $525 / 36 \mathrm{~nm}$, using a Zyla CMOS camera (Andor). For image analysis, ROIs were then chosen and average MCB intensity for each neuron was calculated as an average of last three frames of the plateau and plotted in a scatter plot.

\section{Immunocytochemistry and confocal imaging}

Neurons were plated on 96-well plates as previously described and grown until DIV12-14. Cells were then 
washed in PBS and fixed using 4\% paraformaldehyde (P6148, Sigma) for $30 \mathrm{~min}$ at room temperature and then washed again. Blocking was performed by incubation with 3\% Bovine Serum Albumin (A2153, Sigma) in PBS and staining using a primary antibody against an extracellular epitope of Grin2b (AGC-003, Alomone labs) and a secondary anti-rabbit Alexa488 (Thermo Fisher Scientific). Nuclei were stained with Hoechst 33342 and images were then collected by exciting Alexa488 at $488 \mathrm{~nm}$ and Hoechst at $405 \mathrm{~nm}$, using a $60 \times$ objective and a Zeiss 880 confocal microscope.

\section{mRNA extraction and qPCR}

mRNA was extracted from brain tissue using ReliaPrep ${ }^{\mathrm{TM}}$ RNA Cell Miniprep (Z6010, Promega); mRNA concentration was measured and $500 \mathrm{ng}$ mRNA was used to obtain cDNA by means of the GoScript ${ }^{\mathrm{TM}}$ Reverse Transcription Kit (A5000, Promega), following manufacturer instructions.

The obtained cDNA was subjected to qPCR using SYBR $^{\circ}$ Green JumpStart Taq ReadyMix (S4438, Sigma) and CFX96 Real-Time System (Biorad). Different pairs of primers where then used to quantify the mRNA expression levels of genes of interest:

Cyclophilin A F 5'-CCCACCGTGTTCTTCGACA-3'

Cyclophilin A R 5'-CCAGTGCTCAGAGCTCGAAA-3'

GRIK2 F5'-TGTGGAATCTGGCCCTATGG-3'

GRIK2 R5'-TGAACTGTGTGAAGGACCGA-3'

Grin2b F 5'-CGCCCAGATCCTCGATTTCA-3'

Grin2b R5'-CTGGAAGAACATGGAGGACTCA-3'

MCU F5'-GTCAGTTCACACTCAAGCCTAT-3'

MCU R 5'-TTGAAGCAGCAACGCGAACA-3'

MCURI F 5'-CTTCTGGGAGCAGGAAACTCTA-3'

MCURI R 5'-TGAGTAGCAAACCCATTGTC-3'

MICU1 F5'-GCTCCATAACGCCCAATGAG-3'

MICU1 R5'-GAAGGAGATGAGCCCACACT-3'

\section{Lipid extraction and lipidomics analysis}

Lipids were extracted from brains (dissections performed on newborn pups, $n=3$ per genotype) using Folch extraction (chloroform:methanol $=2: 1$ ) and were analyzed, as previously described [27]. In this configuration, measurements of GBA1 substrate are not able to differentiate between the combined glycosylceramides, and therefore include both glucosylceramides and galactosylceramides.

\section{Statistical analysis}

Image quantification was performed using ImageJ and data were analyzed using GraphPad Prism. When the number of data points (usually corresponding to cell number) was $>150 \quad(n=3$ independent experiments), distribution analysis was performed (frequency distribution or cumulative frequency distribution), while when the number of data points was lower mean \pm SD or mean \pm SEM were used, representing single data points on graphs to properly account for data variability. Tests of normality were performed (Shapiro-Wilk test) to identify normal or non-normal populations. When normal, Student's test or Anova tests (Bonferroni post-test) were used as needed, otherwise the nonparametric Kruskal-Wallis test (Dunns post-test) was used. The chosen tests are clearly indicated in the figure legends; $* p<0.05$, $* * p<0.01$, and $* * * p<0.001$.

\section{Results}

\section{$\mathrm{Gba1}^{+/-}$and $\mathrm{gba1}^{-/-}$neurons show delayed calcium deregulation in response to $10 \mu \mathrm{M}$ glutamate concentrations}

Mixed cultures of neurons and astrocytes were loaded with the low-affinity $\left[\mathrm{Ca}^{2+}\right]_{\mathrm{c}}$ indicator FuraFF-AM and images were acquired over time. Exposure to $10 \mu \mathrm{M}$ glutamate (Fig. 1a) caused the expected rise in $\left[\mathrm{Ca}^{2+}\right]_{c}$, but responses clearly differed between $\mathrm{gbal}^{+/+}, \mathrm{gbal}^{+/-}$, and $\mathrm{gbal}^{-/-}$ neurons. Both the early peak response, $\left(\Delta\right.$ furaFF $\left.F_{\text {early }}\right)$ and responses at later time points differed significantly between genotypes (Fig. 1bii and dii). Cumulative frequency distributions revealed a significant increase in the amplitude of the early glutamate response in both $\mathrm{gbal}^{-/-}$and $\mathrm{gbal}^{+/-}$ neurons, compared with controls (Fig. 1bi, $n=3$ mice per genotype, $N=30-60$ cells per genotype per experiment). In the continued presence of glutamate, the initial transient response was followed in the majority of $\mathrm{gbal}^{-/-}$cells by a delayed increase in $\left[\mathrm{Ca}^{2+}\right]_{\mathrm{c}}$, referred to as DCD, a characteristic response to toxic glutamate concentrations $(100 \mu \mathrm{M}$ or higher) in control cells [28, 29].

At $10 \mu \mathrm{M}$ glutamate, DCD was seen in very few control cells, but was a feature of the majority of $\mathrm{gbal}^{-/-}$cells, while $\mathrm{gbal}^{+-}$cells showed an intermediary response (Fig. 1a-c). The cumulative frequency distribution of the delayed response $\left(\Delta\right.$ furaFF $F_{D C D}-$ Fig. 1di) and the scatter plot of the $\left[\mathrm{Ca}^{2+}\right]_{\mathrm{c}}$ response at $400 \mathrm{~s}$ after glutamate exposure (Fig. 1dii) indicated the percentage of neurons showing DCD (defined as $\Delta$ furaFF $>0.1$ ratio unit). In $\mathrm{gbal}^{+/-}$and in $\mathrm{gbal}^{-1-}$ cultures, about 53 and $60 \%$ of the neurons showed DCD, respectively, while this was seen in only $20 \%$ of neurons in $\mathrm{gbal}^{+/+}$cultures (Fig. 1d, $n=3$ mice per genotype, $N=40-60$ cells per genotype per experiment).

Neuronal responses to $1 \mu \mathrm{M}$ glutamate, at the lower limit of the physiological range [30], also showed differences between genotypes consistent with these data 


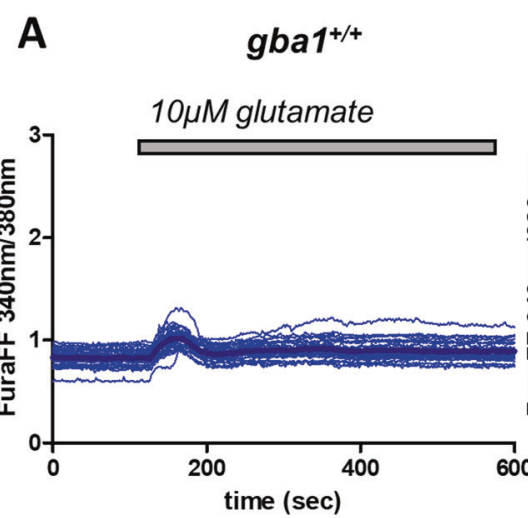

gba1+/-

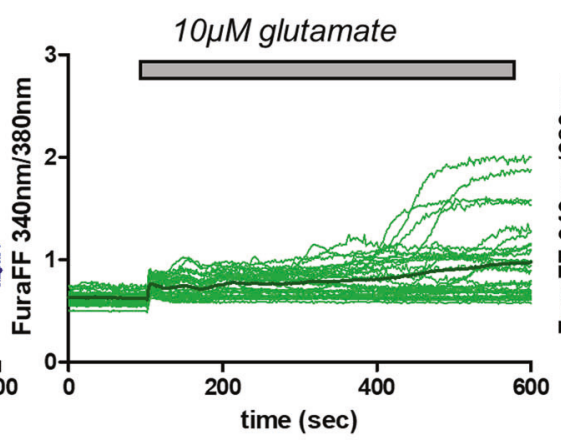

B

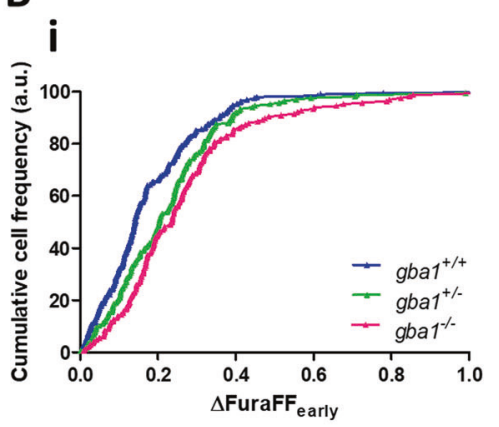

ii

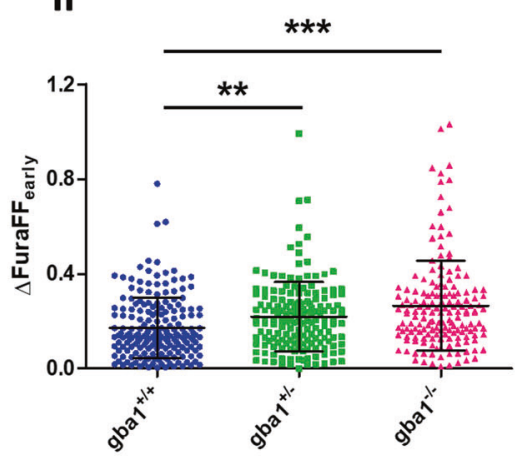

Fig. $1 \mathrm{Gbal}^{+/-}$and $\mathrm{gbal}^{-/-}$neurons show delayed calcium deregulation in response to low glutamate concentrations. a Neuronal cytosolic calcium concentration was measured by fluorescence imaging after labeling neurons with the low-affinity calcium sensor, FuraFF. Changes in $\left[\mathrm{Ca}^{2+}\right]_{\mathrm{c}}$ following exposure of neurons to $10 \mu \mathrm{M}$ glutamate are plotted as a function of time for the different genotypes $\mathrm{gbal}^{+/+}, \mathrm{gbal}^{+/-}$, and $\mathrm{gbal}^{-/-}$, as indicated. The traces reveal a significant difference between the responses of each genotype upon $10 \mu \mathrm{M}$ glutamate stimulation both in term of the immediate response, which was followed by delayed calcium deregulation (DCD) in a large proportion of $\mathrm{gbal}^{-/-}$and a smaller but significant number of $\mathrm{gbal}^{+/-}$ cells $(n=3$ independent experiments, $N=40-60$ cells per genotype per experiment). b (i) The graphs show the cumulative frequency distribution of the peak values of the early response (at about $100 \mathrm{~s}$ ) to $10 \mu \mathrm{M}$ glutamate for the different genotypes and (ii) scatter plots of the peak values and mean \pm SD. The data show a significant increase in

(Supplementary Fig. 1A). $\left[\mathrm{Ca}^{2+}\right]_{\mathrm{c}}$ remained elevated $400 \mathrm{~s}$ after $1 \mu \mathrm{M}$ glutamate in $10-15 \%$ of $\mathrm{gbal}^{+/-}$and $\mathrm{gbal}^{-1-}$ neurons but only in $1 \%$ of $\mathrm{gbal}^{+/+}$neurons. gba1-

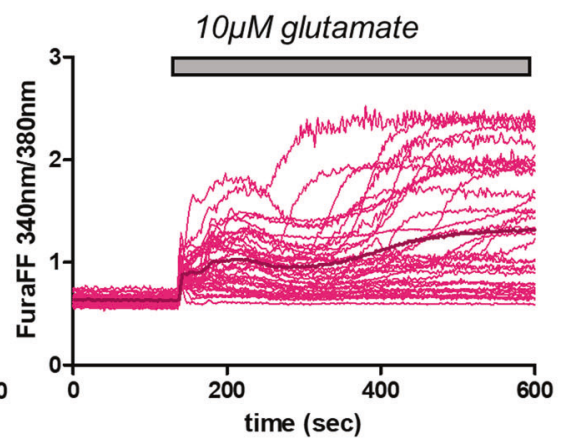

D
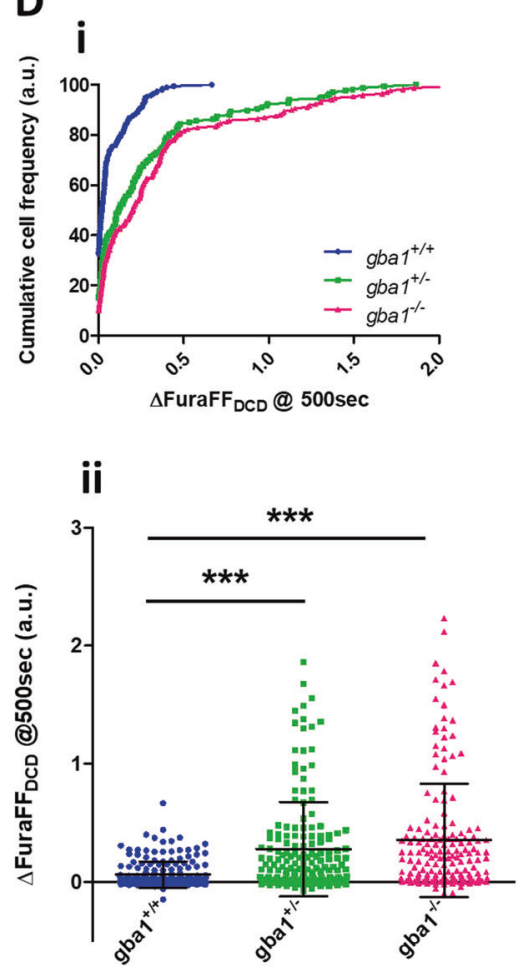

$\left[\mathrm{Ca}^{2+}\right]_{\mathrm{c}}$ in the early response to glutamate in $\mathrm{gbal}^{+/-}$or $\mathrm{gbal}^{-/-}$ compared with $\mathrm{gbal}^{+/+}$(Kruskal-Wallis test, Dunns post-test, ${ }^{*} p<<$ 0.01 and $* * * p<0.001$, respectively). c FuraFF ratiometric images for $\mathrm{gbal}^{+/+}$and $\mathrm{gbal}^{-/-}$neurons (the image excited at $340 \mathrm{~nm}$ divided by that excited at $380 \mathrm{~nm})$, shown at the start of the experiment $(t=0 \mathrm{~s})$ and at $400 \mathrm{~s}$ after exposure to glutamate, showing that $\left[\mathrm{Ca}^{2+}\right]_{\mathrm{c}}$ had fully recovered in the control neurons, while the sustained very high $\left[\mathrm{Ca}^{2+}\right]_{\mathrm{c}}$ levels in the $\mathrm{gbal}^{-/-}$neurons reflect deregulation of $\left[\mathrm{Ca}^{2+}\right]_{\mathrm{c}}$ homeostasis and DCD (scale bar $=25 \mu$ ). d (i) Cumulative frequency distribution of the peak values of DCD (400 s after stimulation) in response to $10 \mu \mathrm{M}$ glutamate for the different genotypes and (ii) relative scatter plots of the peak values and mean \pm SD. These data show the increased percentage of neurons showing DCD $(\Delta$ FuraFF $>$ $0.1)$ in $\mathrm{gbal}^{+/-}$or $\mathrm{gbal}^{-/-}$cells compared with $\mathrm{gbal}^{+/+}$ (Kruskal-Wallis test, Dunns post-test, $* * * p<0.001$ )

In order to determine whether responses to $\mathrm{Ca}^{2+}$ signals arising from different sources also showed deregulation, we explored responses to release ER $\mathrm{Ca}^{2+}$ 
by metabotropic glutamate receptors and to electrical pacing, promoting $\mathrm{Ca}^{2+}$ influx through voltage-gated $\mathrm{Ca}^{2+}$ channels.

Ionotropic receptors were inhibited using $10 \mu \mathrm{M}$ D-AP5 and $20 \mu \mathrm{M}$ CNQX and neurons challenged with $100 \mu \mathrm{M}$ quisqualate, a group I metabotropic receptor agonist [31]. Only very small responses were detectable using the lowaffinity FuraFF (Supplementary Fig. 2A). Experiments with the higher affinity indicator Fura-2, revealed a small but significant reduction in the $\left[\mathrm{Ca}^{2+}\right]_{\mathrm{c}}$ peak response to quisqualate in $\mathrm{gbal}^{-1-}$ neurons (Supplementary Fig. 2B-C). Responses to electrical pacing were undetectable using FuraFF, while measurements with Fura-2 revealed no significant differences in peak responses between genotypes (Supplementary Fig. 2D). Altogether, these data show that DCD is a response only to $\mathrm{Ca}^{2+}$ influx through ionotropic pathways, probably reflecting the much greater $\mathrm{Ca}^{2+}$ load that this represents.

\section{Increased sensitivity of $\mathrm{gbar}^{+/-}$and $\mathrm{gba1^{-1- }}$ neurons to glutamate is not due to different expression of glutamate receptors}

The increased sensitivity to glutamate could reflect altered expression of ionotropic glutamate receptors. The ionotropic glutamate NMDA receptor subunit 2B (Grin2b) and the ionotropic kainate receptor subunit 2 (Grik2) are both lifespan modifier genes in GWAS studies of mouse strains treated with the GBA1 inhibitor, Conduritol B Epoxide (CBE) [32]. Grin $2 b$ mRNA expression is higher in mouse strains in which lifespan is shortened following CBE treatment, suggesting that expression of the glutamate receptor is increased as a secondary effect of GBA1 inhibition and sensitizes the cells. We therefore measured expression levels of mRNA for Grin $2 b$ and for Grik2 in $\mathrm{gbal}^{+/+}, \mathrm{gbal}^{+/-}$, and $\mathrm{gbal}^{-/-}$mouse brains by qPCR. mRNA levels of Grik2 were slightly higher for $\mathrm{gbal}^{+/-}$ neurons compared with the other genotypes, while Grin $2 b$ mRNA levels showed a small but significant decrease in $\mathrm{gbal}^{+/-}$and $\mathrm{gbal}^{-/-}$compared with $\mathrm{gbal}^{+/+}$ (Fig. 2a). However, western blots of brain lysates to quantify Grik2 and Grin2b protein levels (Fig. 2b) $(n=$ 4-5 per genotype) revealed no significant difference among genotypes. Surface analysis for Grin $2 b$ by immunofluorescence [33] and confocal imaging also failed to reveal any significant differences between them (Supplementary Fig. 3). Thus, the increased glutamate sensitivity and DCD is not a consequence of increased glutamate receptor expression.

As DCD is a predictor of neuronal cell death [34, 35], these data show that $\mathrm{gbal}^{-/-}$and $\mathrm{gbal}^{+/-}$neurons are more vulnerable to glutamate-induced $\left[\mathrm{Ca}^{2+}\right]_{\mathrm{c}}$ overload than the $\mathrm{gbal}^{+/+}$.

\section{Lipid homeostasis is differentially altered in the brain of $\mathrm{gba1}^{+/-}$and $\mathrm{gba1^{-/- }}$ mice}

The loss of GBA1 is expected to cause accumulation of its substrate glucosylceramide. Mass spectrometry analysis of lipids extracted from $\mathrm{gbal}^{+/+}, \mathrm{gbal}^{+/-}$, and $\mathrm{gbal}^{-/-}$brains generates measurements of glycosylceramide, which corresponds to both glucosylceramide and galactosylceramide. The resulting data showed accumulation of glycosylceramides only in $\mathrm{gbal}^{-/}$but not in $\mathrm{gbal}^{+/-}$brains, suggesting that one copy of the gene may generate sufficient enzyme to minimize substrate accumulation (Fig. 2b). However, it is important to emphasize that smaller increases in glucosylceramide levels in $\mathrm{gbal}^{+/-}$brains may have been masked when measured together with galactosylceramide, because the latter are more abundant in subpopulations of cells in the brain. In fact, heterozygous GBA pure neurons may present glucosylceramide accumulation [36, 37]. Noteworthy, saturated glycosylceramides (d18:0) were not elevated even in $\mathrm{gbal}^{-1-}$ cells.

Interestingly, other secondary substrates may also be implicated. For example, glycosphingosine accumulation occurs in GD models and in patients with GD [38-40], and even if this does not seem to occur in $\mathrm{gbal}^{+/-}$neurons [40], we cannot exclude a contribution from changes in overall lipid metabolism. Levels of ceramides, products of the GBA1 enzymatic activity, were not affected by the knockout, suggesting activation of compensatory pathways (Fig. 2e). Phosphatidylcholine (PC), lyso-PC, and sphingomyelin were also unaffected (Fig. 2f-h), while phosphatidylethanolamine (PE) and phosphatidylserine (PS), which are important for mitochondrial function and for regulation of autophagy [41-44], were both upregulated in $\mathrm{gbal}^{-/-}$ brains compared with $\mathrm{gbal}^{+/+}$(Fig. 2i-l). PS was increased also in $\mathrm{gbal}^{+/-}$brains, further suggesting that this pathway may contribute to the neuronal pathophysiology.

\section{Low glutamate concentrations cause loss of mitochondrial membrane potential in $\mathrm{gba1}^{+/-}$and gba $^{-/-}$neurons}

The $\left[\mathrm{Ca}^{2+}\right]_{\mathrm{c}}$ increase in DCD associated with glutamate excitotoxicity is closely coupled to collapse of $\Delta \psi \mathrm{m}$ and attributed to impaired $\left[\mathrm{Ca}^{2+}\right]_{\mathrm{c}}$ homeostasis due to ATP depletion and the resultant failure of $\mathrm{Ca}^{2+}$ extrusion from the cytoplasm by $\mathrm{Ca}^{2+}-\mathrm{H}^{+}$ATPases $[29,45]$, but this has not been demonstrated in a disease model.

To further explore the relationship between mitochondrial (dys)function and DCD, we used Rhodamine123, in 'dequench mode' [46], to study time-dependent changes in $\Delta \psi_{\mathrm{m}}$ following exposure to glutamate. After an initial transient depolarization, coincident with the initial $\left[\mathrm{Ca}^{2+}\right]_{c}$ response to glutamate, $\Delta \psi_{\mathrm{m}}$ recovered almost to the 
Fig. 2 Levels of expression of glutamate receptors and massive accumulation of

glycosylceramides are not responsible for increased sensitivity to glutamate in $\mathrm{gbal}^{+/-}$and $\mathrm{gbal}^{-1-}$ neurons. a Expression of the glutamate receptors Grik2 and Grin2b in $\mathrm{gbal}^{+/+}, \mathrm{gbal}^{+/-}$, and $\mathrm{gbal}^{-/-}$ mice brains was measured at the mRNA level by qPCR (shown as scatter plot, mean \pm SEM, $n=3$ brains per genotype).

These data show that Grik2 mRNA was slightly higher in $\mathrm{gbal}^{+/-}$compared with the other genotypes, while Grin $2 b$ mRNA levels were decreased in $\mathrm{gbal}^{+/-}$and $\mathrm{gbal}^{-/-}$compared with $\mathrm{gbal}^{+/+}$, showing that the increased glutamate sensitivity is not attributable to increased glutamate receptor expression (One-way Anova, post-hoc Bonferroni, **p $<0.01$ ).

b Protein expression of the glutamate receptors Grik2 and Grin $2 b$ in $g b a 1^{+/+}, g b a l^{+/-}$, and $\mathrm{gbal}^{-/-}$mice brains were measured by western blot (shown as scatter plot, mean \pm SEM, $n=4-5$ brains per genotype). These data show that the expression of these receptors was unchanged at the protein level (One-way Anova, post-hoc Bonferroni). c-m Analysis of lipidomics performed by mass spectrometry on lipids extracted from $\mathrm{gbal}^{+/+}, \mathrm{gbal}^{+/-}$, and gbal $^{-/-}$brains $(n=3$ brains per genotype, data represented as scatter plot and mean \pm SEM). Glycosylceramide (d18:1) levels were increased in $\mathrm{gbal}^{-1-}$ but not in $\mathrm{gbal}^{+/+}$and $\mathrm{gbal}^{+/-}$ brains (One-way Anova, posthoc Bonferroni, ***p<0.001) (c), suggesting that the enzyme activity produced by a single copy of $G B A 1$ gene is sufficient to avoid substrate accumulation. Curiously, glycosylceramide (d18:0) levels were unchanged (d), as well as Cer, PC, lyso-PC, SM (e-h), while PE and PS are significantly changed in the disease models compared with wild-type brains (i-l)
A
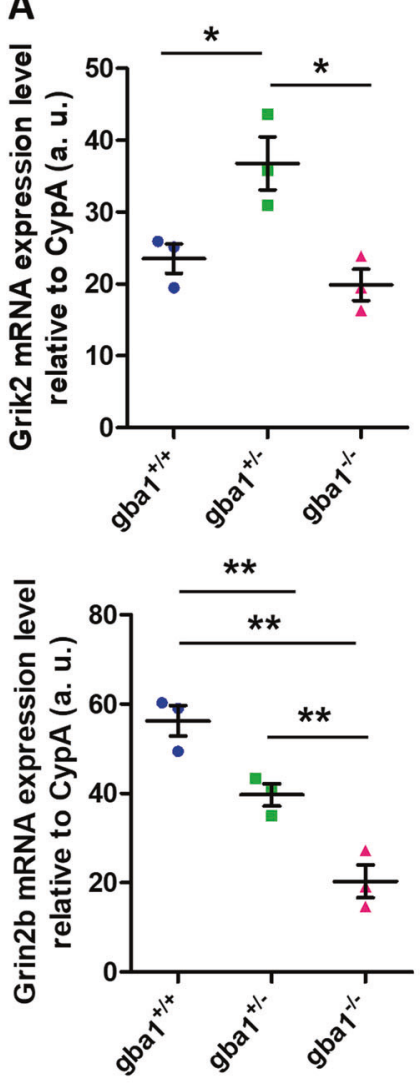

C

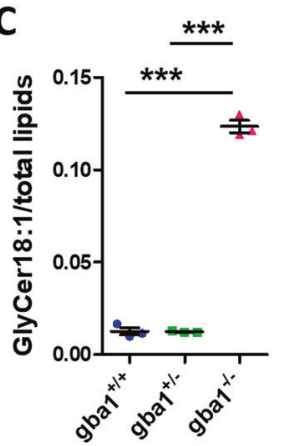

G

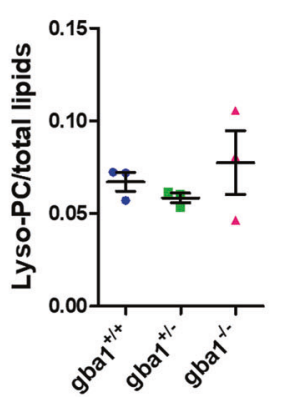

B

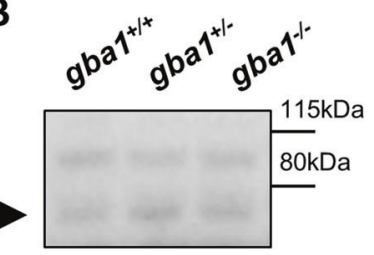

IB: Grik2

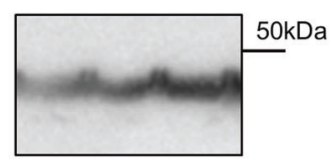

IB: $\beta$-actin

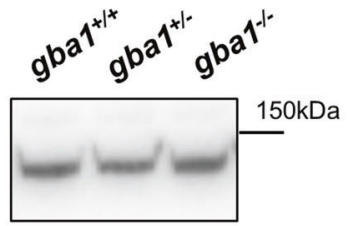

IB: Grin2b

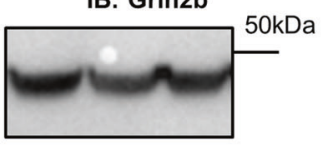

IB: $\beta$-actin
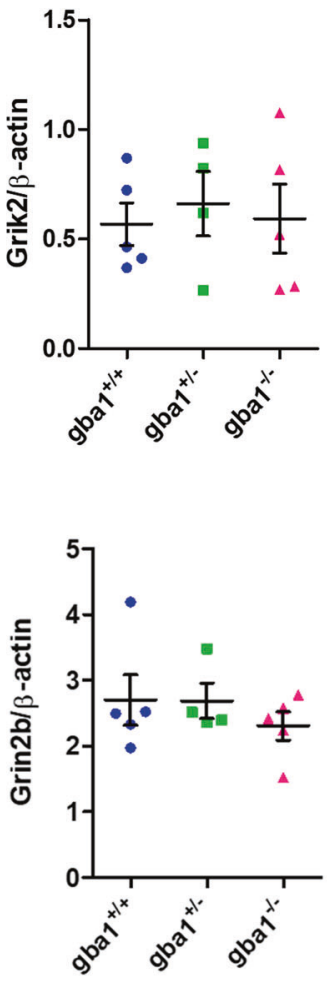

E

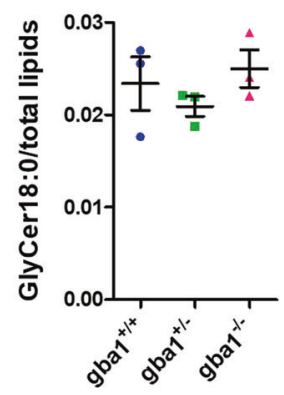

H

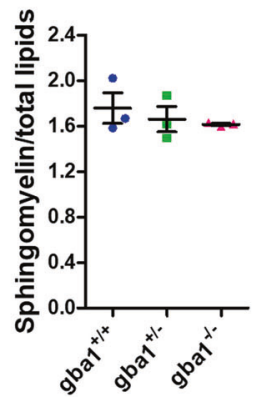

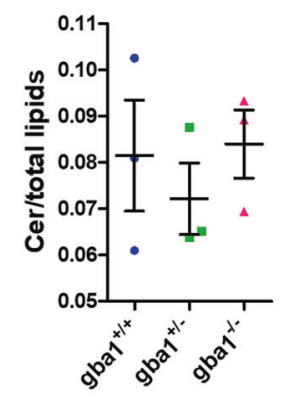

I

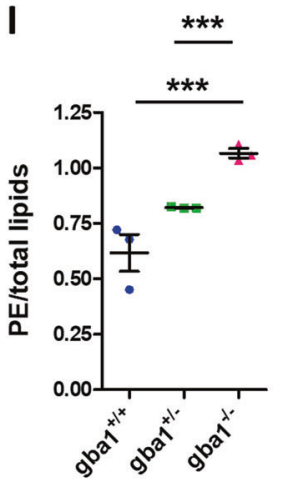

F
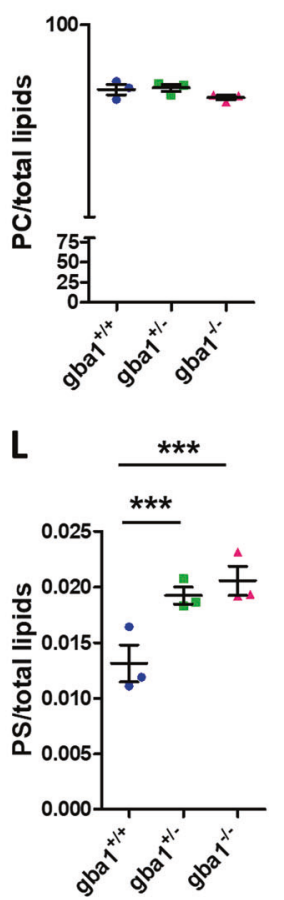

baseline in the majority of $\mathrm{gbal}^{+/+}$neurons, while in $\mathrm{gbal}^{+/-}$and $\mathrm{gbal}^{-/-}$cells a large proportion of cells showed a delayed collapse of $\Delta \psi_{\mathrm{m}}$ (Fig. 3a).
The secondary depolarization, quantified as the percentage change in the normalized Rhodamine123 signal at $400 \mathrm{~s}$ after glutamate stimulation (see methods) was 
A
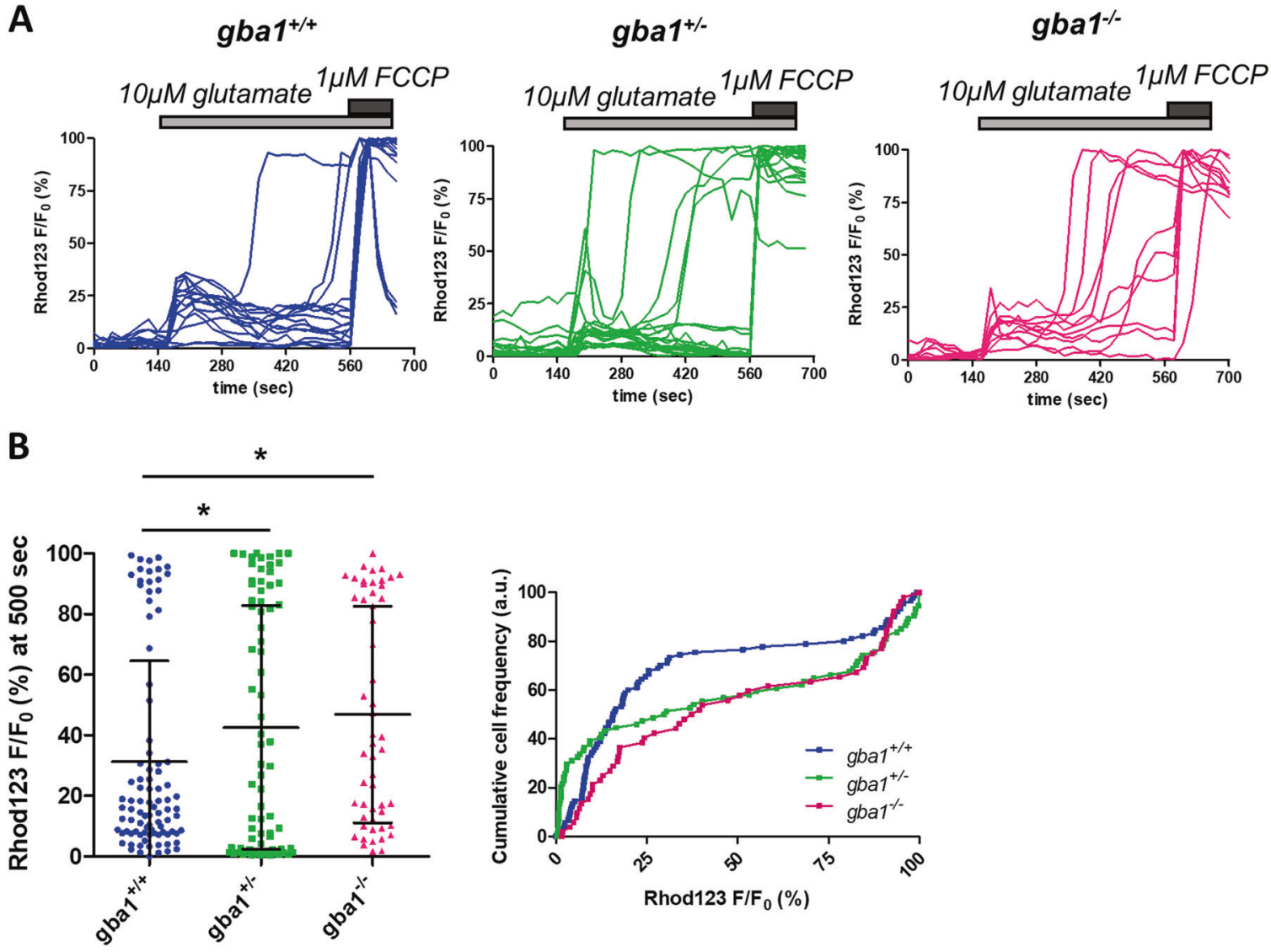

Fig. 3 Low glutamate concentrations cause mitochondrial depolarization in $\mathrm{gbal}^{+/-}$and $\mathrm{gbal}^{-/-}$neurons. a The mitochondrial membrane potential was measured using rhodamine 123 (with the 'dequench protocol') in responses to exposure to $10 \mu \mathrm{M}$ glutamate stimulation and plotted as a function of time for each genotype $g_{b a 1^{+/+}}, g_{b a 1^{+/-}}$, and $g_{b a 1^{-/-}}$. An increase in Rhod 123 fluorescence intensity reports mitochondrial depolarization. The responses to $10 \mu \mathrm{M}$ glutamate were significantly different between $\mathrm{gbal}^{-/-}$and $\mathrm{gbal}^{+/+}$or $\mathrm{gbal}^{+/-}$genotypes, revealing a large depolarization in the $\mathrm{gbal}^{-/-}$and in $\mathrm{gba}^{+/-}$cells $(n=3$ biological replicates, $N=15-25$ cells per

genotype per experiment). b Scatter plots of the mitochondrial depolarization at $360 \mathrm{~s}$ after $10 \mu \mathrm{M}$ glutamate stimulation, expressed as Rhod $123 \mathrm{~F} / \mathrm{F}_{0}$ percentage comprised between the baseline $(0 \%)$ and maximal fluorescence intensity value $(100 \%)$ for the different genotypes. Average values are expressed as mean \pm SD (left panel). Relative cumulative frequency distribution of the mitochondrial depolarization is also shown (right panel), showing a significant mitochondrial depolarization in response to $10 \mu \mathrm{M}$ glutamate in $\mathrm{gbal}^{+/-}$or $\mathrm{gbal}^{-/-}$compared with $\mathrm{gbal}^{+/+}$(Kruskal-Wallis test, Dunns post-test, $* p<0.05$ )

significantly different between genotypes (Fig. 3b): only $23 \%$ of the $\mathrm{gbal}^{+/+}$neurons presented at least $50 \%$ change of signal $400 \mathrm{~s}$ after $10 \mu \mathrm{M}$ glutamate stimulation, while an equivalent depolarization was seen in $42 \%$ of the $\mathrm{gbal}^{+/-}$ and $43 \%$ of the $\mathrm{gbal}^{-/-}$neurons, closely resembling the distribution of the DCD responses.

These measurements confirm the close coupling between collapse of $\Delta \psi_{\mathrm{m}}$ and DCD that we have previously described in other models [29].

\section{Increased sensitivity to glutamate reflects impaired capacity to maintain ATP homeostasis in $\mathrm{gba1}^{+/-}$ and $\mathrm{gba1}^{-/-}$neurons}

The appearance of DCD in response to low glutamate concentrations strongly resembles the glutamate response of neurons following inhibition of oxidative phosphorylation by oligomycin [34, 45, 47] suggesting that glutamate-induced DCD reflects bioenergetic insufficiency in $\mathrm{gbal}^{+/-}$and $\mathrm{gbal}^{-/-}$neurons. We therefore measured dynamic changes in neuronal ATP:ADP ratios in response to glutamate.

Neurons were transfected with the ratiometric fluorescent probe PercevalHR, which reports changes in cytosolic ATP:ADP [24]. Most neurons responded to glutamate with a rapid decrease in the ATP:ADP ratio (Fig. 4a), reported by the probe as a decrease in the ATP sensitive signal and an increase in the ADP sensitive signal (Supplementary Fig. 4). The ATP:ADP ratio recovered over a few minutes in most control cells, but recovery was much slower or absent in the $\mathrm{gbal}^{-/-}$and to a lesser extent in the $\mathrm{gbal}^{+/-}$neurons. 

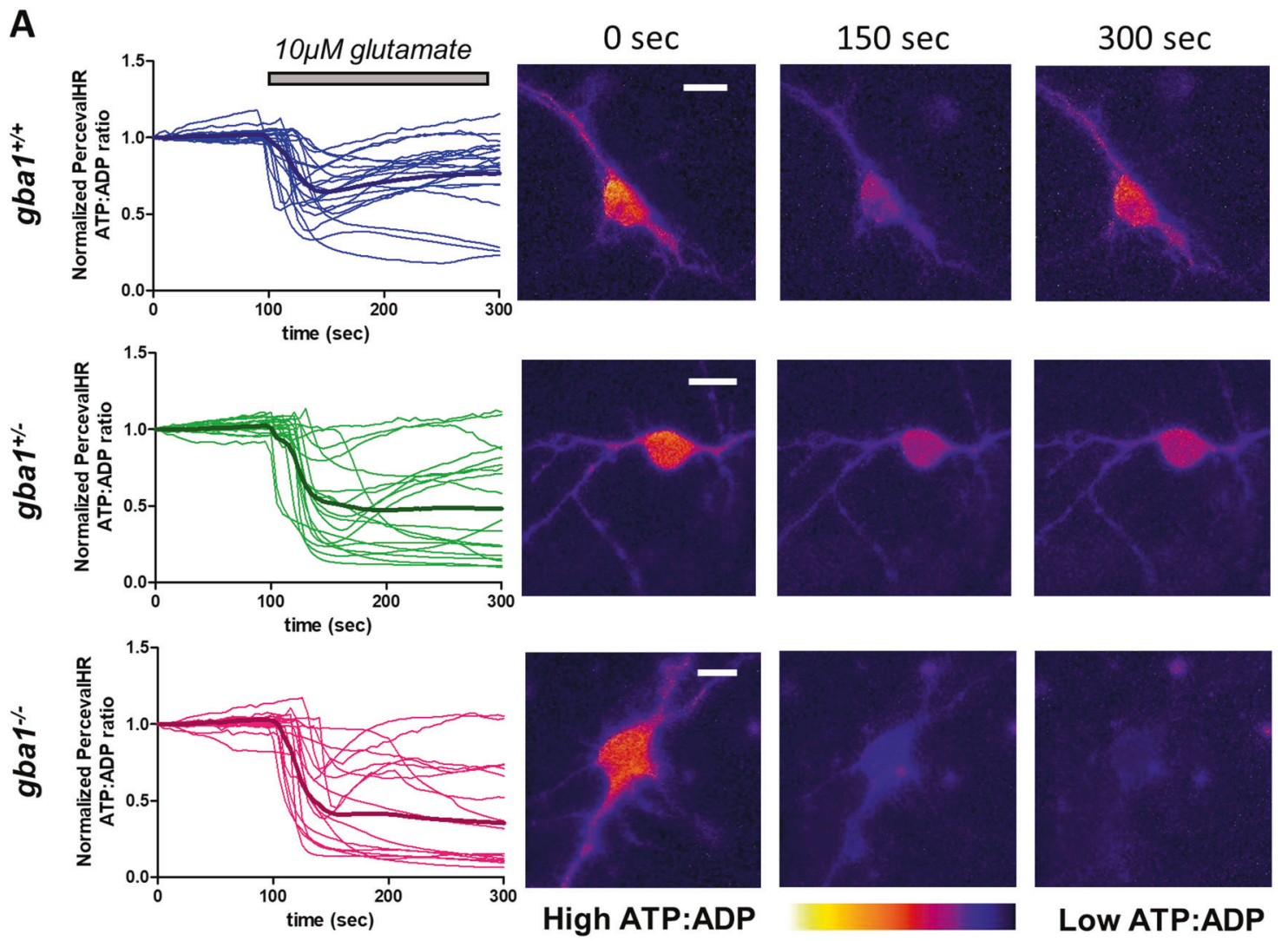

B

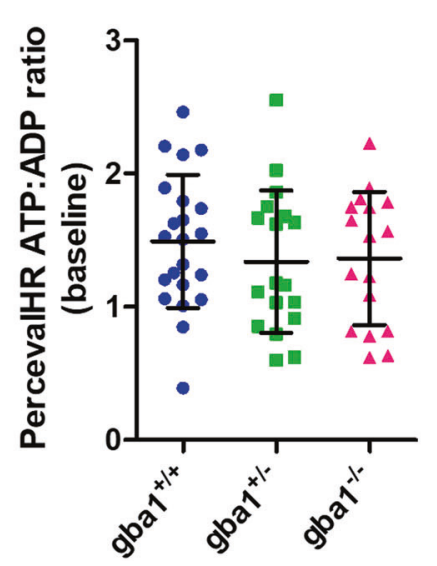

C

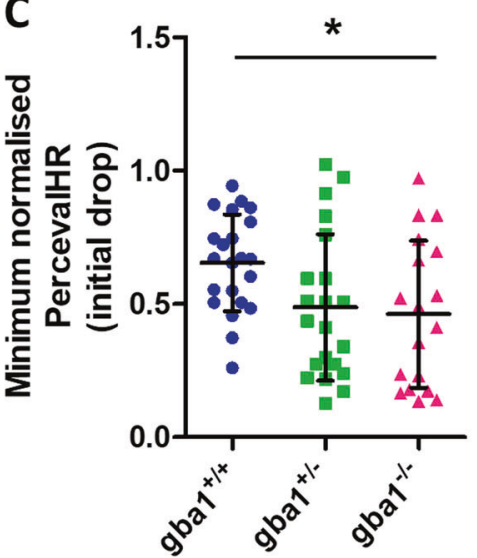

D

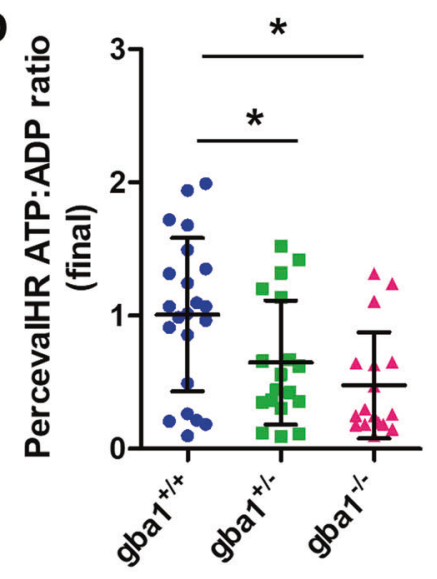

Fig. 4 Low glutamate concentrations cause an irreversible fall of ATP: ADP ratio in $\mathrm{gbal}^{+/-}$and $\mathrm{gbal}^{-/-}$neurons. a The ATP:ADP ratio was measured at the level of single cells using the genetically encoded reporter, PercevalHR, and normalized to the baseline of each response. The PercevalHR ratio following exposure of cells to $10 \mu \mathrm{M}$ glutamate is plotted as a function of time, for each genotype $\mathrm{gba1}^{+/+}, \mathrm{gbal}^{+/-}$, and $\mathrm{gbal}^{-/-}$. Corresponding ratiometric images for three different time points $(0,150$, and $300 \mathrm{~s})$ are also shown $($ scale bar $=10 \mu \mathrm{m}) .10 \mu \mathrm{M}$ glutamate caused a rapid reduction in ATP:ADP, which largely recovered in the majority of $\mathrm{gbal}^{+/+}$cells but failed to recover in $\mathrm{gbal}^{+/-}$and $\mathrm{gbal}^{-/-}$cells. b Scatter plot and mean \pm SD of ATP:ADP ratio in basal conditions (calculated from the raw, non-normalized signals) for the different genotypes $\mathrm{gbal}^{+/+}, \mathrm{gbal}^{+/-}$, and $\mathrm{gbal}^{-/-}$ show no difference at the basal level (Kruskal-Wallis test, Dunns posttest). c Scatter plot and mean \pm SD of ATP:ADP ratio immediately after exposure of cells of each genotype to $10 \mu \mathrm{M}$ glutamate, expressed as the minimum normalized ATP:ADP ratio after stimulation, show that the initial drop in ATP:ADP ratio in $\mathrm{gbal}^{-1-}$ cells was significantly greater than the drop in $\mathrm{gbal}^{+/+}$neurons (Kruskal-Wallis test, Dunns post-test, $\left.{ }^{*} p<0.05\right)$. d Scatter plot and mean \pm SD of ATP: ADP ratio $200 \mathrm{~s}$ after exposure of cells of each genotype to $10 \mu \mathrm{M}$ glutamate (as calculated starting from nonnormalized signals) show that ATP:ADP ratio largely recovered in $\mathrm{gbal}^{+/+}$cells but failed to recover in both $\mathrm{gbal}^{+/-}$and $\mathrm{gbal}^{-/-}$neurons (Kruskal-Wallis test, Dunns post-test, $* p<0.05$ ) 
Quantifying the ATP:ADP ratios before glutamate exposure, immediately after and $200 \mathrm{~s}$ after $10 \mu \mathrm{M}$ glutamate stimulation (Fig. 4b-d), showed that there were no significant differences between basal ATP:ADP ratios (before normalization) among the different genotypes (Fig. 4b), and the initial drop in ATP:ADP ratio was significantly higher in $\mathrm{gbal}^{-/-}$neurons compared with wild-type (Fig. 4c). Moreover, recovery to the baseline was markedly impaired in both $\mathrm{gbal}^{+-}$and $\mathrm{gbal}^{-/-}$cells (Fig. 4d).

Interestingly, the same experiments in control neurons in response to toxic concentrations of glutamate $(100 \mu \mathrm{M})$ (Supplementary Fig. 5), showed an initial decrease in the ATP:ADP ratio, followed by a partial recovery before undergoing a secondary decrease. This behavior was quite distinct from the responses seen in $\mathrm{gbal}^{+/-}$and $\mathrm{gbal}^{-/-}$ neurons upon $10 \mu \mathrm{M}$ glutamate stimulation. However, when control neurons were treated first with $1 \mu \mathrm{M}$ oligomycin, to inhibit oxidative phosphorylation, their responses to $10 \mu \mathrm{M}$ glutamate resembled the responses of the $\mathrm{gbal}^{-1-}$ neurons, showing a decrease that failed to recover. These data further suggest that ATP depletion in $\mathrm{gbal}^{+/-}$and $\mathrm{gbal}^{-/-}$neurons in response to nontoxic glutamate concentrations is a consequence of impaired mitochondrial function.

These data suggest that even though energy homeostatic mechanisms maintain a normal ATP:ADP ratio at rest, the underlying loss of mitochondrial bioenergetic capacity undermines the possibility to match ATP production to meet the increased energy demand following glutamate stimulation.

\section{Mitochondrial calcium uptake is reduced in $\mathrm{gba1}^{-/-}$ and in $\mathrm{gba1}^{+/-}$neurons}

The increased demand imposed on the cell by a $\left[\mathrm{Ca}^{2+}\right]_{\mathrm{c}}$ signal may be matched by an increased energy supply driven by the upregulation of the mitochondrial citric acid cycle in response to a rise in intramitochondrial $\mathrm{Ca}^{2+}$ concentration $\left(\left[\mathrm{Ca}^{2+}\right]_{\mathrm{m}}\right)$ [48-51]. We therefore measured changes in $\left[\mathrm{Ca}^{2+}\right]_{\mathrm{m}}$ in response to $10 \mu \mathrm{M}$ glutamate directly using mitochondriatargeted aequorin (Fig. 5a). Surprisingly, mitochondrial $\mathrm{Ca}^{2+}$ uptake was significantly reduced in both $\mathrm{gbal}^{-/-}$and $\mathrm{gbal}^{+/-}$ neurons compared with $\mathrm{gbal}^{+/+}$.

This is especially significant as the initial transient increase in cytosolic $\left[\mathrm{Ca}^{2+}\right]$ in response to glutamate was increased in the $\mathrm{gbal}^{+/-}$and $\mathrm{gbal}^{-/-}$cells (see above, Fig. 1b), consistent with impaired mitochondrial $\mathrm{Ca}^{2+}$ buffering. Resting cytosolic $\mathrm{Ca}^{2+}$ levels were not significantly different between populations, suggesting that the bioenergetic defect was not severe enough to impair resting $\mathrm{Ca}^{2+}$ homeostasis (Supplementary Fig. 6).

These findings may be attributable to the reduction in $\Delta \psi_{\mathrm{m}}$ seen in $\mathrm{gbal}^{-/-}$and $\mathrm{gbal}^{+/-}$neurons [11]. However, we also explored the expression levels of the components of

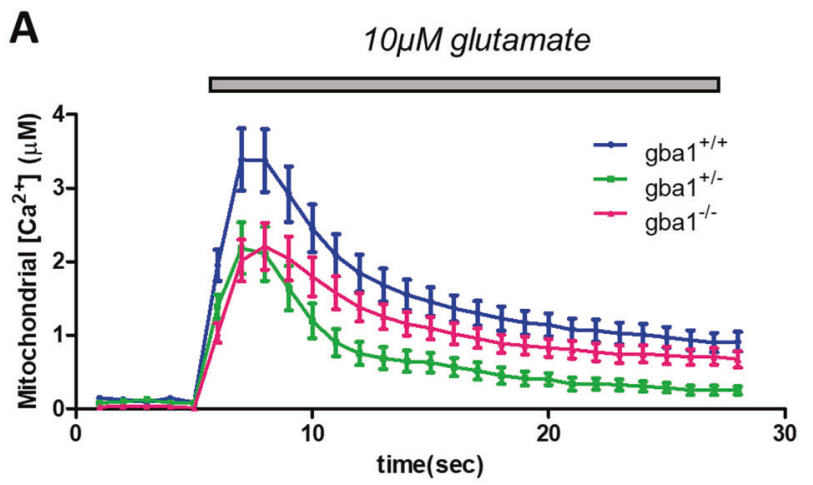

B

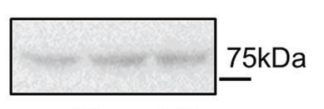

IB: grp75

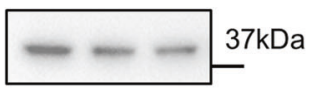

IB: MCU
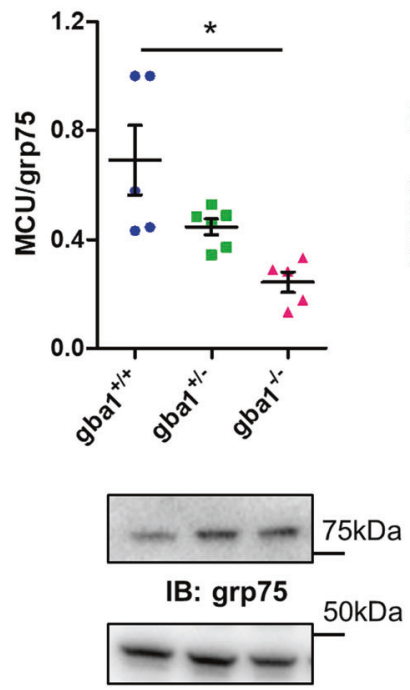

IB: Micu2
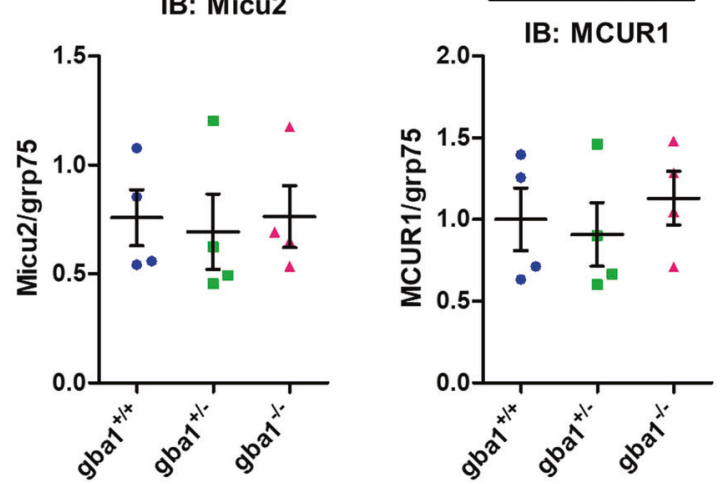

the mitochondrial $\mathrm{Ca}^{2+}$ uniporter complex, which may also contribute to altered mitochondrial $\mathrm{Ca}^{2+}$ uptake $[17,19,52-$ 54]. MCU, EMRE, MICU2, and MCUR1 protein levels were measured by western blot in brains from $\mathrm{gbal}^{+/+}$, $\mathrm{gbal}^{+/-}$, and $\mathrm{gbal}^{-/-}$mice (Fig. 5b). Quantification 
Fig. 5 Mitochondrial calcium buffering capacity is reduced and MCU protein level is decreased in $\mathrm{gbal}^{-/-}$and $\mathrm{gbal}^{+/-}$neurons. a Mitochondria-target aequorin plate reader assay was used to measure mitochondrial $\mathrm{Ca}^{2+}$ uptake in mixed neuronal and astrocytic cultures from $\mathrm{gbal}^{+/+}, \mathrm{gbal}^{+/-}$, and $\mathrm{gbal}^{-/-}$in response to $10 \mu \mathrm{M}$ glutamate. The data show that mitochondrial $\mathrm{Ca}^{2+}$ uptake was significantly reduced in both $\mathrm{gbal}^{+/-}$and $\mathrm{gbal}^{-/}$cells compared with $\mathrm{gbal}^{+/+}(n=3-5$ cultures per genotype, one-way Anova, post-hoc Bonferroni). b Protein expression levels of MCU complex components and MCU regulatory proteins evaluated by western blot in $\mathrm{gbal}^{+/+}, \mathrm{gbal}^{+/-}$, and $\mathrm{gbal}^{-/-}$ brains (data shown as scatter plots and mean \pm SEM, $n=3-5$ brains per genotype). MCU expression was significantly downregulated in $\mathrm{gbal}^{+/-}$ and $\mathrm{gbal}^{-/-}$tissue (One-way Anova, post-hoc Bonferroni, $* p<0.05$ ), while EMRE, MICU2, and MCUR1 expression levels were unchanged

showed that MCU expression was significantly reduced in the $\mathrm{gbal}^{+/-}$and $\mathrm{gbal}^{-/-}$cells, while expression levels of the associated regulatory proteins, EMRE, MICU2, and MCUR1 were not altered ( $n=3-5$ per genotype).

Quantification of mRNA for MCU, EMRE, MICU1, and MCUR1 by qPCR (Supplementary Fig. 7) did not reveal any significant differences ( $n=3$ per genotype), suggesting that changes in MCU expression must be post transcriptionally regulated.

\section{Rates of free radical production are increased in gba $^{-1-}$ neurons}

$\mathrm{Ca}^{2+}$-dependent neuronal injury may be exacerbated by the conjunction of raised $\left[\mathrm{Ca}^{2+}\right]_{\mathrm{m}}$ with oxidative stress [23]. We therefore used dihydroethidium (DHE), a ratiometric fluorescent reporter sensitive to reactive oxygen species (ROS) to determine whether basal rates of free radical production differ in $\mathrm{gbal}^{-/-}$cells (Fig. 6a) [55]. These data showed an increased basal rate of free radical production in $\mathrm{gbal}^{-/}$cells compared with the other genotypes (Fig. 6b). Exposure of cells to $10 \mu \mathrm{M}$ glutamate caused a significant increase in the rate of ROS generation in each genotype, but the relative change was not significantly different between $\mathrm{gbal}^{+/+}, \mathrm{gbal}$ ${ }^{+/-}$, and $\mathrm{gbal}^{-/-}$cultures (Fig. 6b) $(n=3$ independent experiments, $N=10-20$ cells per genotype per experiment).

To address the possibility that the increased rate of resting free radical production in $\mathrm{gbal}^{-/-}$was associated with impaired antioxidant defenses, we measured the expression of superoxide dismutases (SODs) and glutathione (GSH) levels. Western blots of cytosolic SOD1 and mitochondrial SOD2 showed no difference between genotypes ( $n=5$ per genotype) (Fig. 6c). GSH levels were measured using monochlorobimane (MCB) as previously described [26]. MCB reacts with GSH, generating a fluorescent adduct, so a measure of steady-state MCB intensity gives a measure of relative GSH content. MCB intensity in $\mathrm{gbal}^{+/+}, \mathrm{gbal}^{+/-}$, and $\mathrm{gbal}^{-/-}$showed no significant difference between genotypes (Fig. $6 \mathrm{~d}-n=3$ independent experiments, $N=35-40$ cells per genotype per experiment).

\section{Discussion}

The goal of this study was to evaluate the functional consequences of mitochondrial dysfunction on cell physiology in neurons from the transgenic $\mathrm{gbal}^{-/-}$mouse, a model for severe neuropathic GD, and from the $\mathrm{gbal}^{+/-}$mouse, which may illuminate mechanisms of neurodegeneration in GBA1related $\mathrm{PD}$. The functional impact of impaired mitochondrial function is most dramatically revealed in neurons by an impaired capacity to respond to dynamic changes in metabolic demand, such as the increased energy drain imposed by exposure to glutamate. Exposure of the cells to glutamate at concentrations that are innocuous for wild-type cells caused a profoundly dysregulated response in terms of $\left[\mathrm{Ca}^{2+}\right]_{c}$ signaling and mitochondrial metabolism in the $\mathrm{gbal}^{-/-}$and, to a lesser extent, in the $\mathrm{gbal}^{+/-}$neurons.

The $\mathrm{gbal}^{-1-}$ mice suffer from an aggressive form of neurodegeneration, and die only 2 weeks after birth [12], while $\mathrm{gbal}^{+/-}$mice do not show a disease-related phenotype. However, neurons from both $\mathrm{gbal}^{+/-}$and $\mathrm{gbal}$ ${ }^{-1}$ show a significant decrease in $\Delta \psi_{\mathrm{m}}$ and $\mathrm{gbal}^{-/-}$ mixed cultures of neurons and astrocytes also show reduced basal respiratory activity and massively reduced maximal respiratory capacity [11]. We found that neurons from both $\mathrm{gbal}^{-/-}$and $\mathrm{gbal}^{+/-}$mice showed abnormal responses to $10 \mu \mathrm{M}$ glutamate, characterized as DCD, which is normally associated with 'excitotoxicity' in response to much higher concentrations of glutamate. We attribute this vulnerability primarily to the decreased bioenergetic capacity, which is especially severe in the $\mathrm{gbal}^{-/-}$neurons [11], and therefore to the failure to maintain ATP homeostasis in the face of increased energy demand imposed by glutamate.

The decreased mitochondrial $\mathrm{Ca}^{2+}$ uptake that we have shown in both $\mathrm{gbal}^{-/-}$and $\mathrm{gbal}^{+/-}$neurons, will likely contribute to this energetic failure, as it will limit the capacity of the mitochondria to increase ATP production in response to $\left[\mathrm{Ca}^{2+}\right]_{\mathrm{c}}$ signals. The observed reduction in mitochondrial $\mathrm{Ca}^{2+}$ uptake is attributable to the reduced $\Delta \psi_{\mathrm{m}}$ but also to the reduced expression of the MCU protein, which seems to be associated with changes in protein turnover rather than to transcriptional repression.

The small reduction of Grin $2 b$ mRNA in both $\mathrm{gbal}^{+/-}$ and $\mathrm{gbal}^{-/-}$brains may represent another compensatory mechanism, but was not reflected in changes in Grin $2 b$ protein expression, or in the localization of Grin $2 b$ at the plasma membrane. Thus, changes in Grin2b expression or localization are unlikely to be responsible for DCD. Furthermore, responses of $\mathrm{gbal}^{-/-}$neurons to release of ER $\mathrm{Ca}^{2+}$ by metabotropic receptor activation showed a modest reduction, suggesting that the key $\mathrm{Ca}^{2+}$ source that triggers DCD is delivered through ionotropic glutamate receptors. 

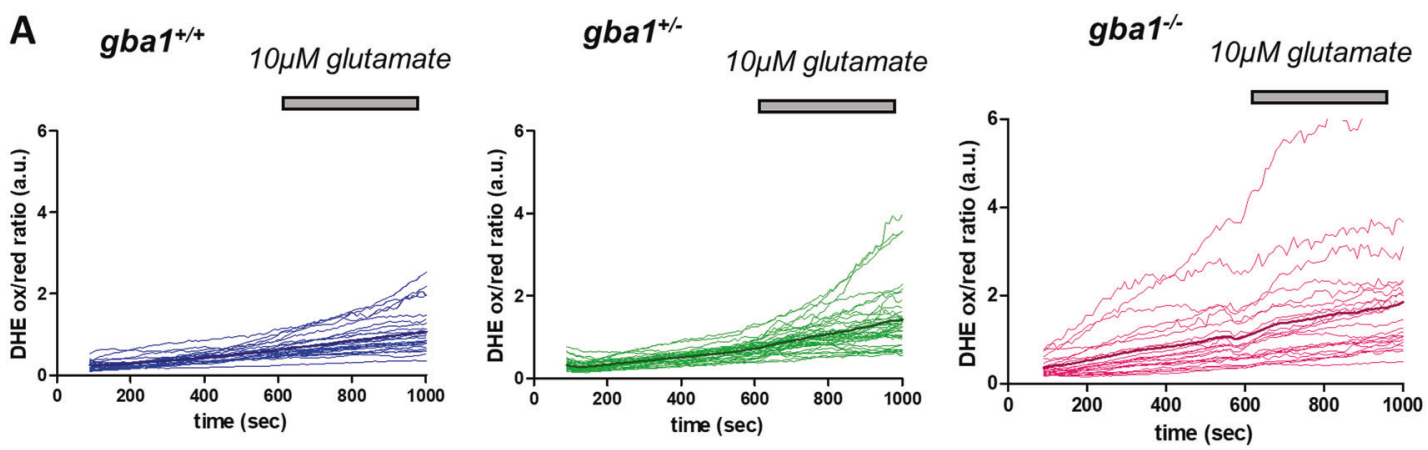

B

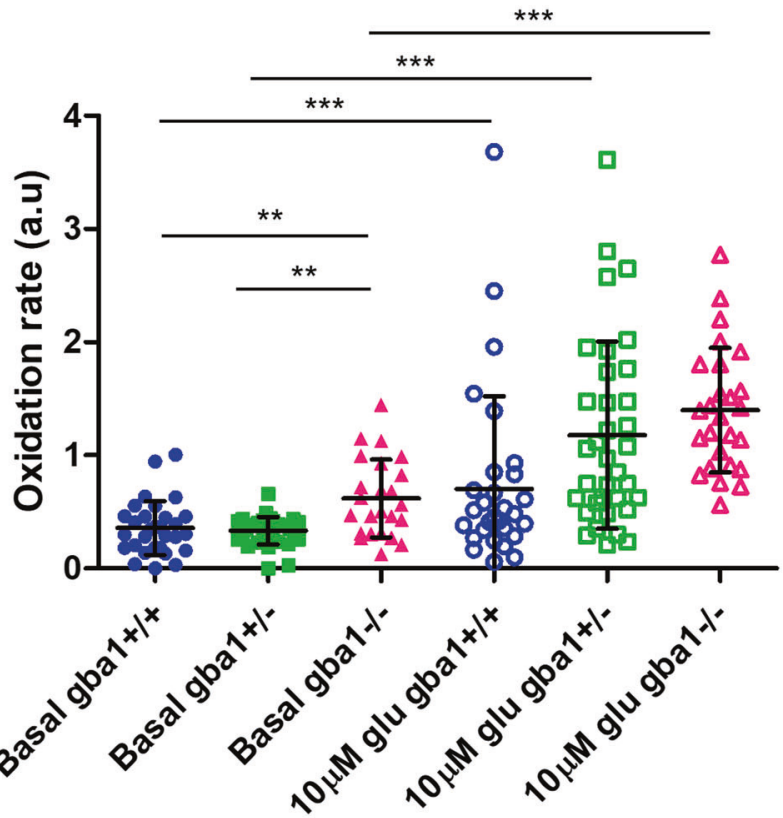

C

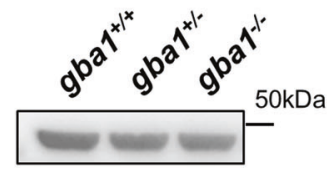

IB: $\beta$-actin

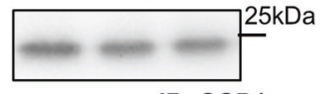

IB: SOD1

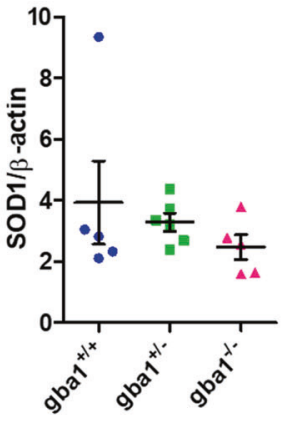

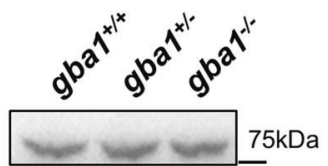

IB: grp75

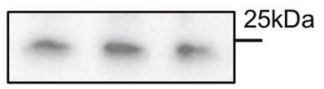

IB: SOD2

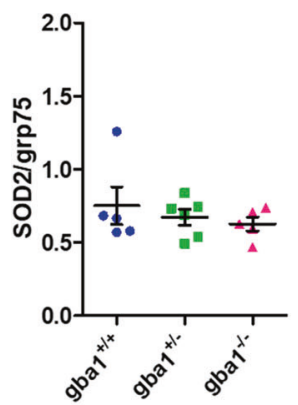

D

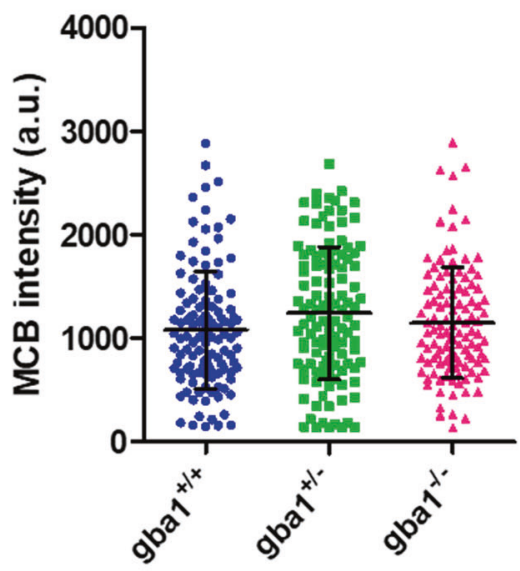

The response to the $\mathrm{Ca}^{2+}$ influx is likely compounded by an increased rate of ROS generation in $\mathrm{gbal}^{-/-}$neurons under basal conditions, as glutamate toxicity is exacerbated by oxidative stress [56].
Interestingly, we have found a marked cellular phenotype in $\mathrm{gbal}^{+/-}$neurons. We previously showed, that $\Delta \psi_{\mathrm{m}}$ is reduced in $\mathrm{gbal}^{+/-}$neurons [11], although defects in respiratory capacity were less severe than in homozygotes. 
Fig. 6 Rates of free radical production are increased in $\mathrm{gbal}^{-/-}$neurons. a The rate of oxidation of Dihydroethidium (DHE) to a red fluorescent product was used to measure the rate of free radical generation with time in live cells. This was calculated as the intensity ratio between the oxidized (red) and the reduced (blue) forms DHE (shown as red and blue in the fluorescence images, respectively), under basal conditions and after $10 \mu \mathrm{M}$ glutamate stimulation. b Representative confocal images of oxidized and reduced DHE in cells (scale bar $=25 \mu \mathrm{m}$ ). Representative DHE oxidation rates quantification as measured from the slopes of the curves showing DHE oxidation over time, before and after $10 \mu \mathrm{M}$ glutamate stimulation for $\mathrm{gbal}^{+/+}, \mathrm{gbal}^{+/-}$, and $\mathrm{gbal}^{-/}$cells (data shown as scatter plots and mean $\pm \mathrm{SD}, n=3$ independent experiments, $N=$ 15-30 cells per genotype per experiment, Kruskal-Wallis test, Dunns post-test, $* * p<0.01$ and $* * * p<0.001)$. c Western blot analysis of the expression levels of antioxidant proteins SOD1 and SOD2 (data shown as scatter plots and mean \pm SEM, $n=5-6$ brains per genotype) normalized to beta-actin and grp75, respectively. The scatter plot showing the result for protein expression suggests that there was no significant difference among the different genotypes (One-way Anova, post-hoc Bonferroni). d Glutathione levels were measured by imaging MCB intensity for neurons from each of the three genotypes (data shown as scatter plots and mean $\pm \mathrm{SD}, n=3$ independent experiments, $N=35-40$ per genotype per experiment). No significant difference was observed (Kruskal-Wallis test, Dunns post-test)

These differences, together with the difference in oxidative stress, that was increased only in $\mathrm{gbal}^{-/-}$neurons, may contribute to the difference of disease phenotype in the $\mathrm{gbal}^{-/-}$and $\mathrm{gbal}^{+/-}$mice. In agreement with our data, a mouse model carrying the heterozygous GBAl PDassociated mutation L444P was shown to have defective mitochondria, supporting a role of impaired bioenergetics in GBA1-associated PD [57]. Dopaminergic neurons at risk of neurodegeneration in PD are physiologically characterized by $\mathrm{Ca}^{2+}$-dependent pace-making activity, while intrinsic $\mathrm{Ca}^{2+}$ buffering capacity is reduced [22], imposing a major energy demand, which will be amplified by mechanisms that compromise bioenergetic reserve, putting these cells especially at risk [58]. Since we have shown that partial depletion of GBA1 in $\mathrm{gbal}^{+/-}$neurons sensitizes neurons to $\mathrm{Ca}^{2+}$ influx and show DCD in response to physiological glutamate concentrations, we suggest that the compromised mitochondrial function in these cells may increase the risk of neurodegeneration in neurons that are already vulnerable because of their normal physiological activity.

It is notable that both $\mathrm{gbal}^{-/-}$and $\mathrm{gbal}^{+/-}$neurons showed similar responses to glutamate and impaired $\left[\mathrm{Ca}^{2+}\right]_{\mathrm{c}}$ handling, suggesting that it is unlikely that the metabolic and signaling defects are simply attributable to the massive accumulation of the GBA1 substrate glucosylceramide, observed in $\mathrm{gbal}^{-/-}$, which was evident despite the presence of galactosylceramides. However, subtle changes of glucosylceramide levels in $\mathrm{gbal}^{+/-}$brains may have been masked by the higher levels of galactosylceramides in the mixed cells. Considering this and the deregulation observed in PE and PS levels in $\mathrm{gbal}^{+/-}$and $\mathrm{gbal}^{-/-}$brains, broader evaluation of lipid homeostasis may help in understanding the pathophysiological mechanisms that couple reduced GBA1 to mitochondrial dysfunction.

Overall, our findings suggest that $\mathrm{gbal}^{-/-}$but also $\mathrm{gbal}^{+/-}$neurons are sensitive to dynamic changes in energy demand caused by an imposed workload, while under basal conditions, both ATP and cytosolic $\mathrm{Ca}^{2+}$ levels in $\mathrm{gbal}^{-/-}$and $\mathrm{gbal}^{+/-}$neurons were not different from the control. This implies the activity of a vicious cycle in which every mechanism enlisted to compensate a homeostatic $\mathrm{Ca}^{2+}$ stress, an increased energy demand and oxidative stress cause further deterioration of cell bioenergetic capacity, triggering a pathological cascade.

Our data highlight a general principle - that in any disease (from age-related neurodegenerative diseases to lysosomal storage disorders) in which mitochondrial bioenergetic capacity is impaired, neurons will become more vulnerable to increased energy demand, which may be sufficient to initiate dysregulated calcium signaling and cell death.

Acknowledgements We would like to thank Prof. Stefan Karlsson for providing us with the GBA1 knockout mouse model. NP was supported by Marie Sklodowska-Curie Individual Fellowship (Horizon 2020 Grant No. 653434), FZ and MD were supported by Michael J. Fox Foundation Target Validation Grant (Grant ID 12159) and GB and MD by the GSK/BBSRC CASE PhD studentship (BB/L502145/ 1). MD was also supported by BBSRC BB/P018726/1. AAR and SNW were part-funded by the UK Medical Research Council grants (G1000709 and MR/N026101/1) and GM received support from the UK Gauchers Association. SNW received part funding from UK Medical Research Council grants MR/R015325/1, MR/P026494/1 and MR/N019075/1 and from SPARKS (17UCL01). AAR is also funded by UK Medical Research Council Grants (MR/R015325/1, MR/ S009434/1, MR/N026101/1 and MR/S036784/1), Action Medical Research (GN2485) and the Wellcome Trust Institutional Strategic Support Fund/UCL Therapeutic Acceleration Support (TAS) Fund (ISSF3/H17RCO/TAS004).

\section{Compliance with ethical standards}

Conflict of interest The authors declare that they have no conflict of interest.

Publisher's note Springer Nature remains neutral with regard to jurisdictional claims in published maps and institutional affiliations.

Open Access This article is licensed under a Creative Commons Attribution 4.0 International License, which permits use, sharing, adaptation, distribution and reproduction in any medium or format, as long as you give appropriate credit to the original author(s) and the source, provide a link to the Creative Commons license, and indicate if changes were made. The images or other third party material in this article are included in the article's Creative Commons license, unless indicated otherwise in a credit line to the material. If material is not included in the article's Creative Commons license and your intended use is not permitted by statutory regulation or exceeds the permitted use, you will need to obtain permission directly from the copyright holder. To view a copy of this license, visit http://creativecommons. org/licenses/by/4.0/. 


\section{References}

1. Brady RO, Kanfer J, Shapiro D. The metabolism of glucocerebrosides. I. Purification and properties of a glucocerebroside-cleaving enzyme from spleen tissue. J Biol Chem. 1965;240:39-43.

2. Smith L, Mullin S, Schapira AHV. Insights into the structural biology of Gaucher disease. Exp Neurol. 2017;298:180-90.

3. Sidransky E, Nalls MA, Aasly JO, Aharon-Peretz J, Annesi G, Barbosa ER, et al. Multicenter analysis of glucocerebrosidase mutations in Parkinson's disease. N Engl J Med. 2009; 361:1651-61.

4. Westbroek W, Gustafson AM, Sidransky E. Exploring the link between glucocerebrosidase mutations and parkinsonism. Trends Mol Med. 2011;17:485-93.

5. Lesage S, Anheim M, Condroyer C, Pollak P, Durif F, Dupuits C, et al. Large-scale screening of the Gaucher's disease-related glucocerebrosidase gene in Europeans with Parkinson's disease. Hum Mol Genet. 2011;20:202-10.

6. Grabowski GA. Phenotype, diagnosis, and treatment of Gaucher's disease. Lancet. 2008;372:1263-71.

7. Malini E, Grossi S, Deganuto M, Rosano C, Parini R, Dominisini $\mathrm{S}$, et al. Functional analysis of 11 novel GBA alleles. Eur J Hum Genet. 2014;22:511-6.

8. Plotegher N, Duchen MR. Mitochondrial dysfunction and neurodegeneration in lysosomal storage disorders. Trends Mol Med. 2017;23:116-34.

9. Plotegher N, Duchen MR. Crosstalk between lysosomes and mitochondria in Parkinson's disease. Front Cell Dev Biol. 2017;5:2011-8

10. Raimundo N, Fernández-Mosquera L, Yambire KF, Diogo CV. Mechanisms of communication between mitochondria and lysosomes. Int J Biochem Cell Biol. 2016;79:345-9.

11. Osellame LD, Rahim Aa, Hargreaves IP, Gegg ME, Richard-londt A, Brandner S, et al. Mitochondria and quality control defects in a mouse model of gaucher disease - links to Parkinson's disease. Cell Metab. 2013;17:941-53.

12. Enquist IB, Lo Bianco C, Ooka A, Nilsson E, Månsson J-E, Ehinger M, et al. Murine models of acute neuronopathic Gaucher disease. Proc Natl Acad Sci USA. 2007;104:17483-8.

13. Rizzuto R, De Stefani D, Raffaello A, Mammucari C. Mitochondria as sensors and regulators of calcium signalling. Nat Rev Mol Cell Biol. 2012;13:566-78.

14. Nicholls DG. Mitochondrial function and dysfunction in the cell: Its relevance to aging and aging-related disease. Int $\mathrm{J}$ Biochem Cell Biol. 2002;34:1372-81.

15. Duchen MR. Mitochondria, calcium-dependent neuronal death and neurodegenerative disease. Pflügers Arch - Eur J Physiol. 2012;464:111-21.

16. De Stefani D, Raffaello A, Teardo E, Szabo I, Rizzuto R. A fortykilodalton protein of the inner membrane is the mitochondrial calcium uniporter. Nature. 2011;476:336-40.

17. Kamer KJ, Mootha VK. MICU1 and MICU2 play nonredundant roles in the regulation of the mitochondrial calcium uniporter. EMBO Rep. 2014;15:299-307.

18. Konig T, Troder SE, Bakka K, Korwitz A, Richter-Dennerlein R, Lampe PA, et al. The m-AAA protease associated with neurodegeneration limits MCU activity in mitochondria. Mol Cell. 2016;64:148-62.

19. Mallilankaraman K, Cardenas C, Doonan PJ, Chandramoorthy HC, Irrinki KM, Golenar T, et al. MCUR1 is an essential component of mitochondrial $\mathrm{Ca}^{+}$uptake that regulates cellular metabolism. Nat Cell Biol. 2012;14:1336-43.

20. Palty R, Silverman WF, Hershfinkel M, Caporale T, Sensi SL, Parnis J, et al. NCLX is an essential component of mitochondrial $\mathrm{Na}^{+} / \mathrm{Ca} 2^{+}$exchange. Proc Natl Acad Sci. 2010;107:436-41.
21. Burbulla LF, Song P, Mazzulli JR, Zampese E, Wong YC, Jeon S, et al. Dopamine oxidation mediates mitochondrial and lysosomal dysfunction in Parkinson's disease. Science (80-). 2017;357:1255-61

22. Surmeier DJ, Schumacker PT. Calcium, bioenergetics, and neuronal vulnerability in Parkinson's disease. J Biol Chem. 2013;288: 10736-41.

23. Reyes RC, Brennan AM, Shen Y, Baldwin Y, Swanson RA. Activation of neuronal NMDA receptors induces superoxidemediated oxidative stress in neighboring neurons and astrocytes. J Neurosci. 2012;32:12973-8.

24. Tantama M, Martínez-François JR, Mongeon R, Yellen G. Imaging energy status in live cells with a fluorescent biosensor of the intracellular ATP-to-ADP ratio. Nat Commun 2013; 4. https://doi. org/10.1038/ncomms3550.

25. Bonora M, Giorgi C, Bononi A, Marchi S, Patergnani S, Rimessi A, et al. Subcellular calcium measurements in mammalian cells using jellyfish photoprotein aequorin-based probes. Nat Protoc. 2013;8:2105-18.

26. Keelan J, Allen NJ, Antcliffe D, Pal S, Duchen MR. Quantitative imaging of glutathione in hippocampal neurons and glia in culture using monochlorobimane. J Neurosci Res. 2001;66:873-84.

27. Ferrazza R, Cogo S, Melrose H, Bubacco L, Greggio E, Guella G, et al. LRRK2 deficiency impacts ceramide metabolism in brain. Biochem Biophys Res Commun. 2016;478:1141-6.

28. Choi DW. Glutamate neurotoxicity in cortical cell culture is calcium dependent. Neurosci Lett. 1985;58:293-7.

29. Abramov AY, Duchen MR. Mechanisms underlying the loss of mitochondrial membrane potential in glutamate excitotoxicity. Biochim Biophys Acta Bioenerg. 2008;1777:953-64.

30. Moussawi K, Riegel A, Nair S, Kalivas PW. Extracellular glutamate: functional compartments operate in different concentration ranges. Front Syst Neurosci. 2011;5:1-9.

31. Thio L, Clifford D, Zorumski C. Characterization of quisqualate receptor desensitization in cultured postnatal rat hippocampal neurons. J Neurosci. 1991;11:3430-41.

32. Klein AD, Ferreira NS, Ben-Dor S, Duan J, Hardy J, Cox TM, et al. Identification of modifier genes in a mouse model of gaucher disease. Cell Rep. 2016;16:2546-53.

33. Pérez-Otaño I, Schulteis CT, Contractor A, Lipton SA, Trimmer JS, Sucher NJ, et al. Assembly with the NR1 subunit is required for surface expression of NR3A-containing NMDA receptors. J Neurosci. 2001;21:1228-37.

34. Vergun O, Keelan J, Khodorov BI, Duchen MR. Glutamate-induced mitochondrial depolarisation and perturbation of calcium homeostasis in cultured rat hippocampal neurones. J Physiol. 1999;519:451-66.

35. Tymianski M, Charlton MP, Carlen PL, Tator CH. Source specificity of early calcium neurotoxicity embryonic spinal neurons in cultured. J Neurosci. 1993;13:2085-104.

36. Schöndorf DC, Aureli M, McAllister FE, Hindley CJ, Mayer F, Schmid B, et al. iPSC-derived neurons from GBA1-associated Parkinson's disease patients show autophagic defects and impaired calcium homeostasis. Nat Commun. 2014;5:1-17.

37. Mazzulli JR, Xu YH, Sun Y, Knight AL, McLean PJ, Caldwell $\mathrm{GA}$, et al. Gaucher disease glucocerebrosidase and $\alpha$-synuclein form a bidirectional pathogenic loop in synucleinopathies. Cell. 2011;146:37-52.

38. Schöndorf DC, Ivanyuk D, Baden P, Sanchez-Martinez A, De Cicco S, Yu C, et al. The NAD+ precursor nicotinamide riboside rescues mitochondrial defects and neuronal loss in iPSC and fly models of Parkinson's disease. Cell Rep. 2018;23:2976-88.

39. Dekker N, van Dussen L, Hollak CEM, Overkleeft H, Scheij S, Ghauharali K, et al. Elevated plasma glucosylsphingosine in Gaucher disease: relation to phenotype, storage cell markers, and therapeutic response. Blood. 2011;118:e118-e127. 
40. Taguchi YV, Liu J, Ruan J, Pacheco J, Zhang X, Abbasi J et al. Glucosylsphingosine promotes $\alpha$-synuclein pathology in mutant GBA-associated Parkinson's disease. J Neurosci. 2017;37: 9617-31.

41. Van Der Veen JN, Lingrell S, Da Silva RP, Jacobs RL, Vance DE. The concentration of phosphatidylethanolamine in mitochondria can modulate ATP production and glucose metabolism in mice. Diabetes. 2014;63:2620-30.

42. Rockenfeller P, Koska M, Pietrocola F, Minois N, Knittelfelder O, Sica V, et al. Phosphatidylethanolamine positively regulates autophagy and longevity. Cell Death Differ. 2015;22:499-508.

43. Hsu P, Shi Y. Regulation of autophagy by mitochondrial phospholipids in health and diseases. Biochim Biophys Acta Mol Cell Biol Lipids. 2017;1862:114-29.

44. Steenbergen R, Nanowski TS, Beigneux A, Kulinski A, Young SG, Vance JE. Disruption of the phosphatidylserine decarboxylase gene in mice causes embryonic lethality and mitochondrial defects. J Biol Chem. 2005;280:40032-40.

45. Khodorov B, Pinelis V, Vergun O, Storozhevykh T, Vinskaya N. Mitochondrial deenergization underlies neuronal calcium overload following a prolonged glutamate challenge. FEBS Lett. 1996; 397:230-4.

46. Duchen MR, Surin A, Jacobson J. Imaging mitochondrial function in intact cells. Methods Enzymol. 2003;361:353-89.

47. Abramov AY, Duchen MR. Impaired mitochondrial bioenergetics determines glutamate-induced delayed calcium deregulation in neurons. Biochim Biophys Acta Gen Subj. 2010; 1800:297-304.

48. Duchen MR. $\mathrm{Ca}^{2+}$-dependent changes in the mitochondrial energetics in single dissociated mouse sensory neurons. Biochem J. 1992;283:41-50.

49. Pardo B, Contreras L, Serrano A, Ramos M, Kobayashi K, Iijima $\mathrm{M}$, et al. Essential role of aralar in the transduction of small
$\mathrm{Ca} 2+$ signals to neuronal mitochondria. $\mathrm{J}$ Biol Chem. 2006;281:1039-47.

50. McCormack JG, Halestrap AP, Denton RM. Role of calcium ions in regulation of mammalian intramitochondrial metabolism. Physiol Rev. 1990;70:391-425.

51. Jouaville LS, Pinton P, Bastianutto C, Rutter GA, Rizzuto R. Regulation of mitochondrial ATP synthesis by calcium: evidence for a long-term metabolic priming. Proc Natl Acad Sci USA. 1999;96:13807-12.

52. De Stefani D, Rizzuto R. Molecular control of mitochondrial calcium uptake. Biochem Biophys Res Commun. 2014;449:373-6.

53. Logan CV, Szabadkai G, Sharpe JA, Parry DA, Torelli S, Childs $\mathrm{AM}$, et al. Loss-of-function mutations in MICU1 cause a brain and muscle disorder linked to primary alterations in mitochondrial calcium signaling. Nat Genet. 2014;46:188-93.

54. Vais H, Mallilankaraman K, Mak D-OD, Hoff H, Payne R, Tanis JE, et al. EMRE is a matrix $\mathrm{Ca}^{2+}$ sensor that governs gatekeeping of the mitochondrial $\mathrm{Ca}^{2+}$ uniporter. Cell Rep. 2016; 14:403-10.

55. Chouchani ET, Pell VR, Gaude E, Aksentijević D, Sundier SY, Robb EL, et al. Ischaemic accumulation of succinate controls reperfusion injury through mitochondrial ROS. Nature. 2014;515:431-5.

56. Forder JP, Tymianski M. Postsynaptic mechanisms of excitotoxicity: Involvement of postsynaptic density proteins, radicals, and oxidant molecules. Neuroscience. 2009;158:293-300.

57. Yun SP, Kim D, Kim S, Kim S, Karuppagounder SS, Kwon SH, et al. $\alpha$-Synuclein accumulation and GBA deficiency due to L444P GBA mutation contributes to MPTP-induced parkinsonism. Mol Neurodegener. 2018;13:1-19.

58. Rivero-Ríos P, Gómez-Suaga P, Fdez E, Hilfiker S. Upstream deregulation of calcium signaling in Parkinson's disease. Front Mol Neurosci. 2014;7:53. 